Discussion Papers

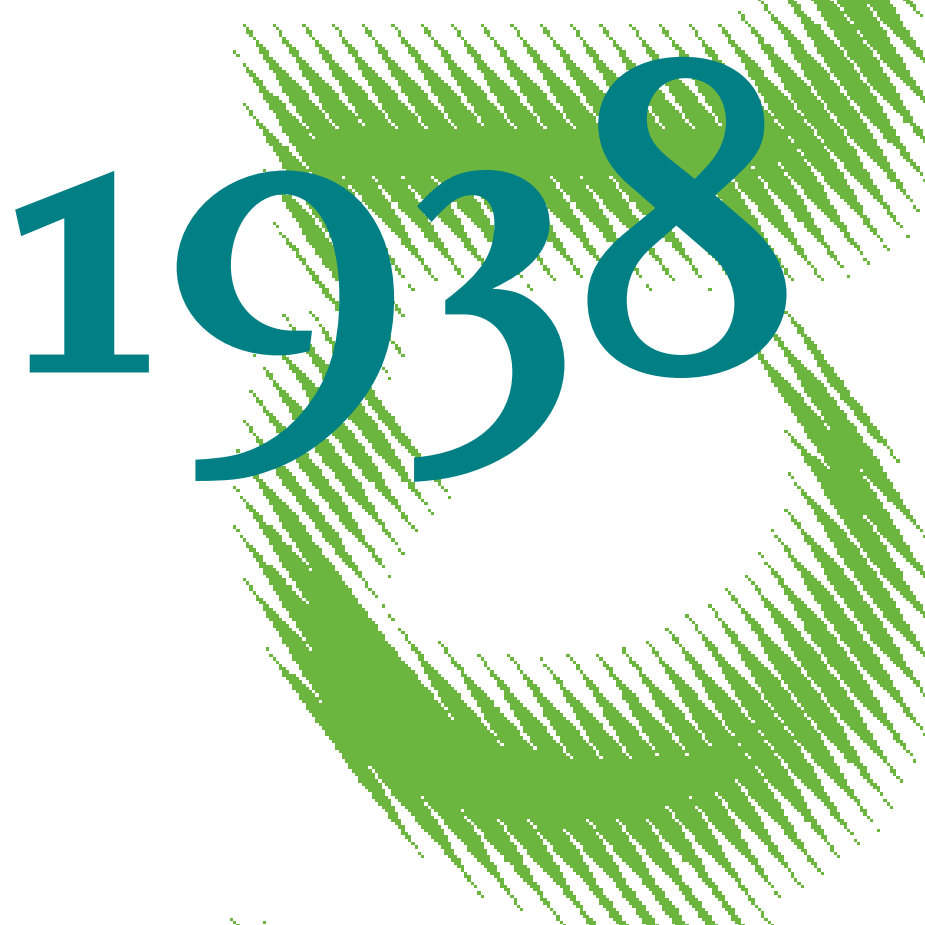

\title{
The Impact of ECB Corporate Sector Purchases on European Green Bonds
}


Opinions expressed in this paper are those of the author(s) and do not necessarily reflect views of the institute.

IMPRESSUM

(C) DIW Berlin, 2021

DIW Berlin

German Institute for Economic Research

Mohrenstr. 58

10117 Berlin

Tel. +49 (30) $89789-0$

Fax +49 (30) $89789-200$

http://www.diw.de

ISSN electronic edition 1619-4535

Papers can be downloaded free of charge from the DIW Berlin website:

http://www.diw.de/discussionpapers

Discussion Papers of DIW Berlin are indexed in RePEc and SSRN:

http://ideas.repec.org/s/diw/diwwpp.html

http://www.ssrn.com/link/DIW-Berlin-German-Inst-Econ-Res.html 


\title{
The Impact of ECB Corporate Sector Purchases on European Green Bonds
}

\author{
Franziska Bremus $^{1} \quad$ Franziska Schütze $^{2} \quad$ Aleksandar Zaklan $^{3}$
}

March 24, 2021

This paper analyzes the effect of the ECB's Corporate Sector Purchase Programme (CSPP) and the recent Pandemic Emergency Purchase Programme (PEPP) on the yields of eligible green bonds, a new but rapidly growing segment of the corporate bond market. We exploit these policy changes using a difference-in-differences strategy, with ineligible corporate green bonds issued in euro, U.S. dollars and Swedish crowns as comparison groups. We find that both programs significantly improve financing conditions for eligible green bonds, thereby increasing the attractiveness of these instruments to issuers and of the euro area as a location of issuance. The effects of the CSPP and PEPP are heterogeneous, both in terms of average impact and persistence of the effects. Yield differences between eligible and ineligible green bonds can last for more than six months. Our analysis informs the debate about new financing options for firms as well as about effects of asset purchase programs on the transition towards a less carbon-intensive economy.

\section{JEL: E52, E58, G12, G18, Q54}

Keywords: green bonds, bond yields, monetary policy, corporate sector purchase programme (CSPP), pandemic emergency purchase programme (PEPP)

\footnotetext{
${ }^{1}$ DIW Berlin; e-mail: fbremus@diw.de.

${ }^{2}$ DIW Berlin; e-mail: fschuetze@diw.de.

${ }^{3}$ DIW Berlin, Mohrenstr. 58, 10117 Berlin, Germany; e-mail: azaklan@diw.de, ph: +49-30-89789-515. Corresponding author.

We thank Anne Steuernagel and Joel Kohen for excellent research assistance. All errors are our own. Part of this research was funded by the Mercator Foundation via the project "Rahmenprogramm Sustainable Finance" (grant number 19026202).
} 


\section{Introduction}

While the European Central Bank (ECB) often highlights the market neutrality of its asset purchase programs, such as the Corporate Sector Purchase Programme (CSPP) or the more recent Pandemic Emergency Purchase Programme (PEPP), this may not always be the case with respect to the financing conditions of firms in different market segments. The available evidence suggests that eligible bonds benefit more strongly from asset purchase programs, at least for a certain period of time, than the entire bond market does. CSPP, for example, had a strong price effect on bonds eligible for the program (Todorov, 2020: De Santis et al., 2018).

From a climate policy perspective, asset purchase programs can be an effective way of fostering segments of the bond market that channel investment into firms' sustainability projects, such as greenhouse gas emission mitigation or adaptation to climate change to decrease their future earnings risks. The improved financing conditions can enable firms issuing green bonds eligible for the asset purchase programs to undertake such investments at lower cost. As a consequence, the transition to a less carbon-intensive economy may be supported by such monetary policies. On the downside, due to the much larger size of the conventional bond market, asset purchase programs also support conventional bonds issued to finance energy- and carbon-intensive activities. This may foster high-carbon technology lock-in through preferable financing conditions for such investments, compared to less emission-intensive ones (Matikainen et al., 2017; Dafermos et al., 2020). This tension becomes even more relevant since the latest expansion of asset purchases by the ECB through the PEPP, which made the ECB an even more important buyer in the market for both green and conventional corporate bonds 11 With a volume of 1850 bn EUR at the end of 2020, the PEPP makes up around $10 \%$ of the overall bond market within the euro area ${ }^{2}$ Furthermore, the ECB held around $18 \%$ of the universe of eligible corporate sector bonds under its asset purchase program in 2020, both of conventional and green bonds $3^{3}$

Against this background, the goal of this paper is to analyze the impact of ECB corporate asset purchase programs on financing conditions in the market for green bonds.

\footnotetext{
${ }^{1}$ Campiglio et al. (2018) and Svartzman et al. (2020) discuss potential solutions to recent controversies regarding the role of the central bank and financial regulators in managing climate-related risks and helping to mitigate climate change.

${ }^{2}$ According to data from the Bank for International Settlements, total debt securities outstanding in the euro area in the second quarter of 2020 were at 18.3 tn euro https://stats.bis.org/statx/srs/table/c1?p=20202c $=$

${ }^{3}$ see Figure 9 in a 2020 speech by Isabel Schnabel at https://www.ecb.europa.eu/press/key/date/2020/html/ecb.sp200717 1556b0f988.en.html
} 
More precisely, we address the question of whether and how yields on corporate green bonds eligible for purchases under the CSPP and PEPP are affected by increased demand from the ECB in comparison to non-eligible corporate green bonds issued in euro, U.S. dollars, and Swedish crowns.

To the best of our knowledge, this paper is the first to systematically analyze causal implications of central bank asset purchase programs on yields in the green bond market. In addition to the sustainability perspective, evaluating the impacts of asset purchase programs on the green bond market is also an interesting case study of the consequences of a sudden strong demand pull by a credible new market participant in a nascent segment of the corporate bond market $4^{4}$ In addition, we contribute to the literature by examining the impact of the PEPP on corporate bond yields, and, hence, on funding conditions of eligible corporate bonds.

To identify causal effects on the yields of eligible vs. non-eligible green bonds, we pursue a difference-in-differences strategy and exploit exogenous variation in the demand for green bonds in the euro area by focusing on the announcement of the ECB's CSPP in 2016, and of the PEPP in 2020. As our data contain weekly bond yields together with additional bond-level and issuer-level information, we are able to identify four alternative control groups of corporate green bonds: euro-denominated bonds issued by non-financial corporations and by financial institutions; U.S. dollar-denominated bonds, and Swedish crown-denominated bonds, a rapidly emerging segment of the European and global green bond market.

The following key findings emerge from our analysis. First, ECB asset purchase programs improve financing conditions for eligible green bonds relative to ineligible ones, increasing the attractiveness both of these instruments to issuers and of the euro area as a location of issuance for green bonds. Second, the effects of the CSPP and PEPP are heterogeneous. The CSPP is estimated to decrease yields of eligible green bonds by between 18 and 33 basis points (bp) relative to the four comparison groups of euro and non-euro-denominated green bonds. This translates into a differential impact with respect to relative financing conditions vis-à-vis each comparison group, depending on the difference in average yields between treatment and comparison groups. The baseline impact of

\footnotetext{
${ }^{4}$ The market for green corporate bonds has been growing rapidly since 2016. In the CSPP-eligible corporate sector universe, the share of green bonds has increased from around $2.5 \%$ in 2016 to around $5 \%$ in 2020 , see

https://www.ecb.europa.eu/press/key/date/2020/html/ecb.sp200717 1556b0f988.en.html
} 
the PEPP varies more strongly, with an estimated effect of 135 bp compared to ineligible green corporate bonds, 15 bp compared to Swedish crown-issued green bonds and no significant effect compared to euro-denominated green bonds issued by financial institutions. Third, the impact of ECB asset purchase programs differs in terms of persistence. Some of the effects of the programs are fairly long-lived, such as the effect of the PEPP on eligible green corporate bonds compared to euro-denominated non-eligible green bonds issued by non-financial corporations, which lasted for about 30 weeks after the program's announcement. In other cases, the impact is immediately absorbed by market participants, e.g. the effect of the PEPP on eligible green corporate bonds compared to non-eligible green bonds issued by financial institutions.

Our findings are of clear policy relevance in at least two dimensions. First, we show that both ECB asset purchase programs were effective at improving financing conditions for issuers of eligible assets in the increasingly important market segment of green bonds. Second, the impact on the euro-denominated green bond market shows that asset purchase programs can be effective policy options in fostering a transition towards a low-carbon economy.

Our research relates to two main strands of literature, namely the literature investigating the price and quantity effects of asset purchase programs in different regions and markets. Regarding the literature investigating the effects of the CSPP on (all, i.e. predominantly conventional) eligible and non-eligible bonds, applying a difference-in-difference analysis, Todorov (2020) finds that the CSPP increased liquidity and prices of eligible corporate bonds, with yields dropping $30 \mathrm{bp}$, on average, after the announcement. Additionally, the issuance of eligible corporate bonds increased by about $25 \%$. Similarly, De Santis et al. (2018) analyze the impact of the CSPP on corporate bond prices using panel techniques. They identify a similar decline in bond spreads of $25 \mathrm{bp}$ for eligible corporate bonds compared to $20 \mathrm{bp}$ for all ineligible corporate bonds. Findings by De Santis and Zaghini (2019) point to an increase in bond issuance of around $14 \%$ for eligible bonds compared to non-eligible bonds. Zaghini $(2019)$ assesses the impact of the CSPP on bond spreads in the primary market at the time of issuance. His results indicate significant effects on purchased bonds and indirectly on other bonds as well. Similarly, other studies investigate the effect of quantitative easing programs in the US (Krishnamurthy and Vissing-Jorgensen, 2011; Yang and Zhou, 2017; Duca et al., 2016; Fratzscher et al., 2018; Swanson, 2020) and the UK (Joyce et al., 2011; Christensen and Rudebusch, 2012; 
Breedon et al., 2012). Rogers et al. (2014) compare the effects of unconventional monetary policy on asset prices in different regions, namely the US, UK, EU and Japan.

Among these studies on the effects of asset purchase programs, there is a small but growing literature concerned with the financing conditions of carbon-intensive versus lowcarbon companies. Matikainen et al. (2017) and Dafermos et al. (2020) present descriptive evidence that ECB corporate bond purchases contains a high share of bonds from carbonintensive sectors compared to their contribution to employment and economic output. However, specific price effects or causal effects are not investigated.

Turning to the second closely related strand of literature, several studies investigate price differences between green and conventional bonds and the effect of environmental preferences therein. Goss and Roberts (2011) find that in the US, firms where concerns about social responsibility issues are known need to pay higher interest rates on average. Similarly, Chava (2014) finds that banks charge higher interest rates and investors expect higher returns from firms faced with environmental concerns. Albuquerque et al. (2019) find supporting evidence that engaging in corporate social responsibility decreases firm risk and increases firm value.

Tang and Zhang (2020) present evidence that additionally, green bond issuance has a positive effect on stock prices of the issuer, indicating a signalling effect. Flammer (2020) finds that issuers of green bonds improve their environmental performance and attract long-term investors, whereas she finds no price difference between green bonds and a conventional bonds issued by the same firm. These results are also in line with a signalling effect. Zerbib (2019) shows that investors' pro-environmental preferences lead to slightly lower yields for green bonds, compared to their counterfactual conventional bonds, using a global dataset. Kapraun and Scheins (2019) find that only green corporate bonds with a large size and green bonds from governments or supranational entities profit from lower yields. Furthermore, they show that the credibility of green bonds, indicated by a third-party verification or by being listed in a green bond segment, is the most important determinant of their yields. For the U.S. municipal bond market Karpf and Mandel (2018) find that green bonds trade at higher prices than comparable conventional bonds since 2015. Findings by Baker et al. (2018) suggest similar price difference for U.S. municipal and corporate green bonds, especially when green bonds are externally verified. So far, the influence of asset purchase programs on the yields of green corporate bonds has not been investigated in the literature. 
The remainder of this paper is structured as follows. Section 2 provides background information on central bank asset purchasing programs in general and the CSPP and PEPP in particular. Section 3 describes our dataset and presents stylized facts on the market for green bonds. Section 4 describes the research design, while Section 5 presents the results. Section 6 summarizes and concludes.

\section{Background}

The focus of this analysis is the evolution of bond yields in the small but growing segment of green corporate bonds around the announcement of the ECB's CSPP in March 2016 and its extension within the PEPP in 2020. In this section, first, we discuss the timing and design of asset purchases programs by the ECB, the Federal Reserve (Fed) and the Swedish central bank (Riksbank). The goal is to set the stage for our choice of control groups and identification strategy that allows us to analyze if green bonds eligible under the CSPP and PEPP are affected differently than non-eligible green bonds. Second, we provide a brief discussion of potential transmission channels of central bank asset purchases to the bond market.

\subsection{Central bank asset purchase programs}

In response to the financial and the sovereign debt crisis in the euro area, the ECB launched its asset purchase program (APP) in 2014. Such unconventional monetary policy instruments aim at ensuring price stability and at increasing the lending capacity so that real activity is supported. The first phase of the APP started in March 2015. Under the public sector purchase program (PSPP) public sector bonds were bought at a volume of about 60 bn EUR per month.

In March 2016, the ECB announced an extension of its asset purchases from 60 to 80 bn EUR, partly by adding a corporate sector purchase program (CSPP) (Figure 1). This was the first ECB-program targeted at the corporate bond market in order to support financing conditions in the real economy, and it "caught the market by complete surprise" (Todorov, 2020). The CSPP was announced on March 10, 2016 and implemented on June 8, 2016 with a monthly volume of purchases of around 10 bn EUR.5 In March 2016, the governing council of the ECB also decided on further measures, such as an additional

\footnotetext{
${ }^{5}$ For an overview of the asset purchase programme see:

https://www.ecb.europa.eu/mopo/implement/app/html/index.en.html
} 
reduction in policy rates as well as a series of targeted longer-term refinancing operations (TLTROs), which provide long-term funding to banks if they provide loans to non-financial institutions and households.

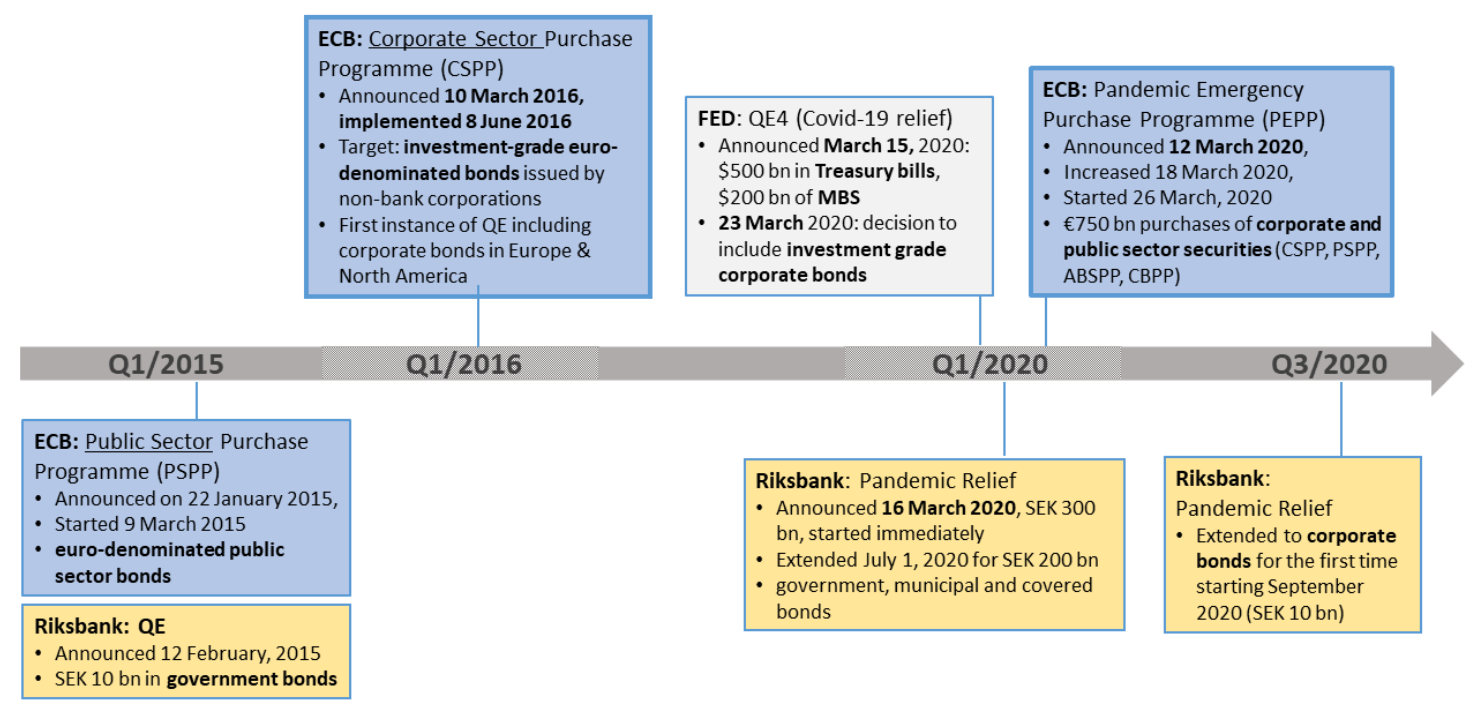

Figure 1: Timeline of asset purchase programs in the EU, US and Sweden

At the time of announcement of the CSPP, no other corporate sector purchase programs were announced or implemented in the US or Sweden (see Figure 1). Sweden has also introduced a public sector purchasing program for government bonds on February 12th 2015, but no corporate sector program. In the United States, the Fed started its first quantitative easing (QE) program much earlier, in 2008. There were three QE programs running from 2008 until 2014. Mainly two types of assets were bought, sovereign bonds and mortgage-backed securities, while corporate bond purchases were not implemented until very recently ${ }^{6}$

On March 12, 2020, in response to the start of the Covid-19 pandemic in Europe, the ECB announced an additional asset purchase program (Figure 1). On March 18, 2020, its large-scale additional Pandemic Emergency Purchase Program (PEPP) with an initial volume of 750 bn EUR (including both public and corporate sector bond purchases) was announced. The program was implemented on March 26, and was later on expanded to 1850 bn EUR until the end of 2020 7 At the same time, the ECB announced to conduct additional longer-term refinancing operations (LTROs) as well as additional asset

\footnotetext{
${ }^{6}$ https://www.federalreserve.gov/newsevents/pressreleases/monetary20200615a.htm

${ }^{7}$ https://www.ecb.europa.eu/mopo/implement/pepp/html/index.en.html
} 
purchases of 120 bn EUR until the end of 2020, with a strong share of the private sector program. Policy rates were kept unchanged.

Shortly before, on March 15, 2020, the Fed announced a large-scale asset purchasing program (QE4) in response to the Covid-19 pandemic, including 500 bn USD treasury bill purchases and 200 bn USD of mortgage backed securities. On March 23, 2020, for the first time, the Fed announced to also purchase investment grade corporate bonds. The Riksbank announced its Pandemic Relief program on March 16, 2020 with purchases of up to 300 bn SEK of government, municipal and covered bonds, which was extended on July 1st. On September 1, 2020 the Riksbank announced to also purchase corporate sector bonds for the first time, starting on September 14.

\subsection{Transmission channels to bond markets}

The effects of asset purchase programs on bond yields are unclear ex ante, due to several possible transmission channels, some of which have contrary effects on yields. The literature on quantitative easing effects describes different possible transmission channels and effects of asset purchase programs. The main effect of QE is its impact on long-term interest rates. Through asset purchases, which increase demand, central banks commit to low-interest rates, also called signalling channel (Meaning and Zhu, 2011). Another potential effect is the portfolio rebalancing effect, which occurs when markets are segmented into different asset classes and investors try to find alternative investments in another, usually more risky, asset class (without additional demand from central banks) (Krishnamurthy and Vissing-Jorgensen, 2011; Meaning and Zhu, 2011; Abidi and Miquel-Flores, 2018: Zaghini, 2019). However, the safety premium channel might dampen this effect. As discussed in Krishnamurthy and Vissing-Jorgensen (2011) there is significant demand for long-term safe assets, e.g. from institutional investors such as pension funds (at the cut-off between investment grade and non-investment grade securities). These risk averse investors will avoid investing into non-investment grade securities, despite lower yields due to additional demand from central banks.

Knock-on effects between segments of bond markets due to asset purchase policies may occur not only within, but also between currency areas. Duca et al. (2016) investigate international spillover effects of the U.S. QE programs, finding that it had a large impact on corporate bond issuance, especially in emerging markets. This indicates that portfolio rebalancing across regions is another transmission channel of QE-policies. Fratzscher et al. 
(2018) also find evidence that especially QE2 and QE3 have led to portfolio rebalancing towards non-US regions (based on data from equity and bond funds). However, Rogers et al. (2014) notes that spillovers are found mainly in one direction, from U.S. monetary policy to non-US yields.

\section{Data}

To analyze the impact of corporate sector purchases of the ECB on the yields of eligible green bonds under the CSPP and the PEPP, we use two main data sources. In the following, we first describe the dataset and then provide descriptive statistics on the market for green bonds.

\subsection{Data sources}

Information on the the timing of corporate bond purchases and on the detailed eligibility criteria under the CSPP and PEPP are taken from the ECB website and respective press releases 8

Bond- and issuer-level data are taken from Bloomberg. We make use of data for all green bonds available from Bloomberg issued in euro, U.S. dollars, and Swedish crowns. We retrieve weekly averages of bond yields and all other bond- and issuer characteristics for the period 2013 - 2020. For the regression analysis, we cover the sample period from January 4 - December 30, 2016 (52 weeks) for the CSPP, and from January 6 - October 30, 2020 (44 weeks) for the PEPP.

Besides yields to maturity, we use information on maturities, currency denomination, country of incorporation of the issuer, bond ratings by Fitch, Moodys and S\&P, Bloomberg Industry Classification System (BICS) and NACE Level-3 codes, amounts outstanding, and amounts issued. In order to reduce the number of missing values for ratings, additional data points are sourced from EIKON $9^{9}$ We then apply the respective eligibility criteria to identify the bonds that are eligible for purchase by the ECB. Under the CSPP, the eligibility criteria announced on April 21, 2016 included all bonds that

- are denominated in euro

\footnotetext{
${ }^{8}$ See $\quad$ https://www.ecb.europa.eu/press/pr/date/2016/html/pr160421. en.htmlandhttps //www.ecb.europa.eu/mopo/implement/pepp/html/pepp - qa.en.html

${ }^{9}$ In cases where there is no bond-level rating available but a rating at the issuer level is, we follow the guidelines by the ECB and use the latter to evaluate whether a bond is investment grade or not.
} 
- are issued by a non-bank corporation

- are issued by a corporation established in the euro area as defined by the country where the issuer is incorporated

- have a minimum remaining maturity of six months and a maximum remaining maturity of 30 years

- and are rated investment grade by at least one of the major rating agencies.

Under the PEPP, which was announced on March 12 and extended on March 18, 2020, these eligibility criteria were adjusted to include securities of a remaining maturity of at least 28 days for those with an initial maturity of one year or less. For securities with an initial maturity of 366/367 days or more, the remaining maturity at the time of purchase has to be at least six months and 31 years at most.

In order to identify green bonds, we use the Bloomberg classification. We consider all bonds labeled as "green bond" in the Bloomberg fixed income search for the initial sample. The Bloomberg green bonds indicator is based on the Green Bonds Priciples (GBP) and identifies bonds as "green" if their proceeds are used for projects that promote climate change mitigation, adaptation or other environmentally sustainable goals. 10

\subsection{Descriptive overview}

The global green bond market remains small compared to the overall bond market, but has been growing rapidly. It contains green bonds from different types of issuers, whose proceeds are used for climate-friendly projects Flammer (2020). The first green (supranational) bonds were issued by the European Investment Bank (EIB) and the World Bank in 2007 and 2008. The first green corporate and green municipal bonds followed in 2013. According to the Climate Bond Initiative, global annual issuance increased from below 50 bn USD (45 bn EUR) in 2015 to 270 bn USD (236.8 bn EUR) in 2020111 From 2016 to 2017, the aggregate amount issued more than doubled both in Europe (from 24.4 to 57.9 bn USD, or 22 to 51.2 bn EUR) and North America (from 21.1 bn to 50.6 bn USD, or 19 to 44.8 bn EUR)

\footnotetext{
${ }^{10}$ The GBP are voluntary guidelines by the International Capital Market Association to increase transparency and disclosure in the process of issuing bonds with environmental benefits. They are intended to inform both investors and issuers. See https://www.icmagroup.org/assets/documents/Regulatory/Green-Bonds/Green-Bonds-PrinciplesJune-2018-270520.pdf

${ }^{11}$ https://www.climatebonds.net/2021/01/record-2695bn-green-issuance-2020-late-surge-sees-pandemicyear-pip-2019-total-3bn
} 
The European and U.S. markets for green bonds are the fastest growing as well as the largest segments of the global green bond market during our sample periods ${ }^{12}$ In our empirical analysis we additionally consider corporate green bonds issued in Swedish crowns which make up for an important part of the European green corporate bond market outside the euro area.

We start our analysis by descriptively examining the evolution and key characteristics of the green bond market based on bond-level data provided by Bloomberg for the 2013 2020 period. Regarding issuer type, we focus on corporations given our goal of evaluating the effects of the ECB's corporate sector purchase programs CSPP and PEPP. In line with the empirical model presented below, in the following, we focus on corporate green bonds issued in euro, U.S. dollars and Swedish crowns for which data on yields are available.

To present general information on the evolution of the size of the green bond market, Figure 2 depicts annual data for three important segments of the global green bond market, namely for bonds issued in euro, U.S. dollars and Swedish crowns. Figure 2(a) plots the number of green bonds issued per year for all green bonds and for the subsample of public sector green bonds, whereas Figure 2(b) shows the cumulative annual amounts issued by currency. Both the number and volumes of green bonds have strongly expanded since 2013, particularly after 2016. While the number of green bonds in our dataset was 17 in 2013, it increases up to 1527 in 2020, with corporate bonds gaining in importance relative to public sector bonds. At the same time, the cumulative amounts issued also rose significantly, and stood at roughly 600 bn EUR at the end of 2020 .

This strong increase in the volumes of green bonds was particularly driven by the European market, accounting for nearly $60 \%$ of the cumulative amounts issued at the end of the observation period. When focusing on the market for green bonds issued in euro, we observe an increase in the number of green bonds from three in 2013 to 595 in 2020 with the share of corporate green bonds rising from $33 \%$ to $81 \%$ during this period.

Figure 3 shows histograms of the bottom 95\%-percentile of the amounts issued (in million EUR) of green bonds over time and by sector. ${ }^{13}$ Figure 3(a) underscores the increase in the number of green bonds over time. Regarding the size of the amounts issued, it appears that the majority of issues is distributed between amounts of a few

\footnotetext{
${ }^{12}$ Asia-Pacific, especially China, became an important market for green bonds since 2016. Annual issuance increased from 27 bn USD in 2016 to 46.5 bn USD in 2019 according to CBI. However, China is not considered in this analysis, due to differences in its financial market structure and monetary policy.

${ }^{13} \mathrm{We}$ do not show the largest values in the top $5 \%$-percentile for reasons of readability.
} 
(a) annual number of bonds issued

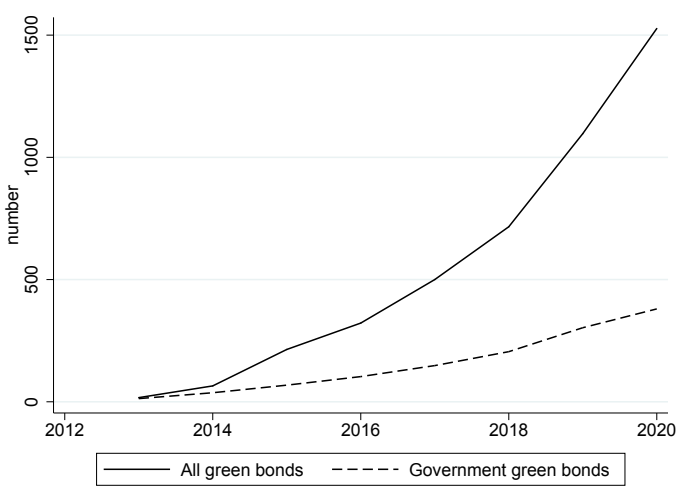

(b) cumulative amounts issued

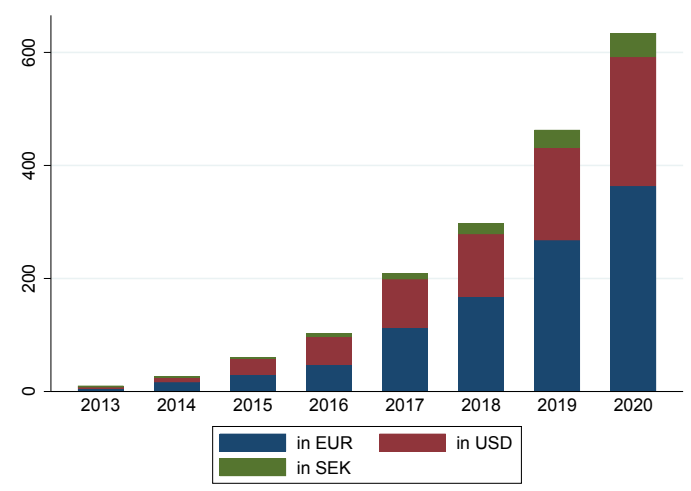

Note: This figure plots the number of all green bonds, as classified by Bloomberg, for bonds issued in euro, U.S. dollars and Swedish crowns (LHS), as well as the cumulative annual amounts issued (RHS). Source: Bloomberg.

Figure 2: Evolution of the green bond market

thousand EUR and one billion EUR. Interestingly, the histograms show a kink around a value of $500 \mathrm{mn}$ EUR as of 2015, which is also evident when looking at the European market only. Figure 3(b) reveals that bonds issued by financial corporations (BICS sector 35 ), by corporations in the utilities sector (BICS sector 39), and by the public sector (BICS sector 50) drive this pattern.

The most important sectors issuing green bonds in our sample, as measured by the shares in the total amount issued between 2013 and 2020 are, besides the public sector, financial firms and firms from the utilities sector (Table 1, column (4)). One reason for the small number of eligible green bonds in our CSPP sample, thus, relates to the fact that a large part of green bonds are issued by governmental institutions and banks which are not eligible for central bank corporate bond purchases. Regarding the number of bonds issued, the energy sector (BICS sector 34) is also important with a similar number of observations as utilities. Yet, given the small average and especially median amount issued (columns (5)-(6)), the energy sector only represents a share of about $2 \%$ in the total amount issued.

Summing up, when considering all green bonds issued in euro, U.S. dollars and Swedish crowns with information on yields, it appears that during the 2013 - 2020 period, the average bid-yield to maturity lies at about $3.7 \%$ for the corporate green bonds and varies quite significantly, while the average amount issued amounts to roughly $300 \mathrm{mn}$ EUR (not reported). Given some large outliers observed for these variables, we carefully check our estimation sample in the analysis presented in Section 5.1 and winsorize yields at the $2.5 \%$ and $97.5 \%$ levels. 
(a) by year

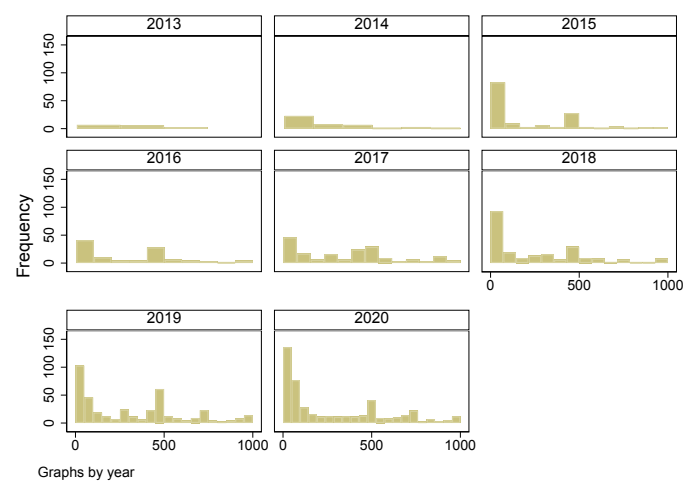

(b) by sector

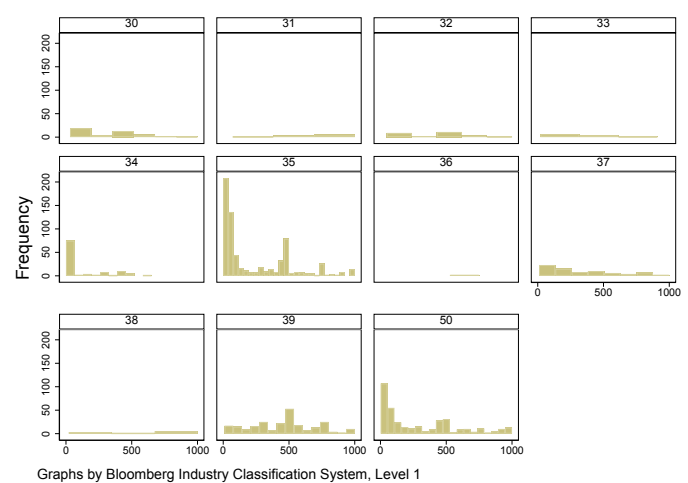

Note: This figure plots the histograms of the amount issued (in million euro) of all green bonds provided by Bloomberg, issued in euro, U.S. dollars and Swedish crowns. For reasons of readability, we cut observations at the 95\%-percentile. Sectors are classified according to the Bloomberg Industry Classification System (BICS) with 30=Materials, 31=Communications, 32=Consumer Discretionary, $33=$ Consumer Staples, 34=Energy, 35=Financials, 36=Health Care, 37=Industrial, 38=Technology, $39=$ Utilities, $50=$ Government. Source: Bloomberg.

Figure 3: Size distribution of green bonds, amount issued

\section{Research design}

\subsection{Identification}

The causal effect of the announcement of corporate bond purchases by the ECB on yields to maturity of green bonds eligible for the programs is identified through a comparison of within-bond changes in yields of eligible bonds with those not eligible for the CSPP and PEPP, conditional on common shocks at the weekly frequency, unobserved yet fixed bond-level characteristics, and country-time or sector-time fixed effects.

As we are unable to observe yields for the counterfactual scenario of eligible green bonds not being eligible, we must rely on the parallel trends assumption, i.e. that postCSPP/PEPP yields in the control group(s) are a fair representation of the counterfactual development of the yields of green corporate bonds eligible under these programs. For the credibility of the parallel trends assumption it is important that pre-CSPP/PEPP trends in yields between treatment and control groups evolve in parallel and that concurrent policy interventions can be excluded. We probe the validity of the parallel trend assumption in two ways. First, we descriptively present average yields in treatment and control groups (Section 5.1). Second, we estimate an event study design and inspect point estimates and confidence bands for pre-CSPP/PEPP periods (Section 5.3). The idea is to estimate, for each pre-treatment time period, whether the evolution of the outcome variable significantly 
Table 1: Green bond market by sector

\begin{tabular}{ccccccc}
\hline \hline & $(1)$ & $(2)$ & $(3)$ & $(4)$ & $(5)$ & $(6)$ \\
BICS Level 1 & Freq. & Percent & $\begin{array}{c}\text { Cum. } \\
\text { Market share }\end{array}$ & $\begin{array}{c}\text { Av. amt. iss. } \\
\text { Med. amt. iss. }\end{array}$ \\
\hline 30 & 3,887 & 2.25 & 2.25 & 2.31 & 338.02 & 325 \\
31 & 405 & 0.23 & 2.49 & 0.91 & 731.68 & 700 \\
32 & 2,527 & 1.47 & 3.95 & 1.97 & 407.53 & 500 \\
33 & 1,334 & 0.77 & 4.73 & 0.55 & 319.44 & 200 \\
34 & 23,589 & 13.68 & 18.41 & 1.83 & 68.14 & 8.89 \\
35 & 56,326 & 32.66 & 51.07 & 27.71 & 265.50 & 77.41 \\
36 & 262 & 0.15 & 51.22 & 0.20 & 574.77 & 638.93 \\
37 & 7,711 & 4.47 & 55.69 & 5.29 & 497.12 & 265 \\
38 & 915 & 0.53 & 56.23 & 1.10 & 774.35 & 907.77 \\
39 & 24,758 & 14.36 & 70.58 & 19.92 & 549.75 & 500 \\
50 & 50,728 & 29.42 & 100.00 & 38.20 & 592.24 & 250 \\
\hline \hline
\end{tabular}

Note: This table summarizes the sectoral amounts issued (in million euro) of all green bonds with non-zero observations on yields provided by Bloomberg, issued in euro, U.S. dollars and Swedish crowns. Sectors are classified according to the Bloomberg Industry Classification System (BICS) with $30=$ Materials, $31=$ Communications, $32=$ Consumer Discretionary, $33=$ Consumer Staples, 34=Energy, $35=$ Financials, $36=$ Health Care, $37=$ Industrial, $38=$ Technology, $39=$ Utilities, $50=$ Government. Columns (1) - (3) show the frequency of observations in absolute and relative terms, columns (4) and (6) summarize the share of each sector in the total amount issued between 2013 and 2020 and the average and median amount issued by sector, respectively. Source: Bloomberg.

differs between bonds assigned to the treatment and control group. As the policy was not in place during the pre-treatment period, point estimates of the policy variable that are insignificantly different from zero during the pre-treatment period indicate the validity of parallel trends.

Concurrent policies that may affect yields represent a potential threat to identification. However, as shown in Section 2 , no other concurrently introduced corporate sector purchasing policies affect yields either in the treatment or in the control groups during our sample period. Despite monetary policy actions that were announced at the same time as the CSPP, we follow the related literature and disentangle the effects of the CSPP on the yields of green bonds, focusing on control groups that include corporate (green) bonds only and that are unaffected by other central bank corporate sector purchase programs (bonds issued in Swedish crowns and in U.S. dollars). For the evaluation of the effects of the corporate sector purchases under the PEPP, we disregard U.S. dollar-denominated green bonds due to the concurrent corporate sector purchases by the Fed in March 2020. Sweden only added corporate sector bonds in September 2020. Therefore, corporate green bonds denominated in Swedish crowns can be used as a control group during the announcement and implementation of the PEPP in March 2020. 
Table 2: Summary statistics for the regression samples

\begin{tabular}{|c|c|c|c|c|c|}
\hline & Obs. & Mean & SD & Min & Max \\
\hline \multicolumn{6}{|c|}{ CSPP } \\
\hline \multicolumn{6}{|c|}{ Control group: ineligible EUR-denominated green non-financial bonds } \\
\hline Yield to maturity & 936 & 2.20 & 2.21 & 0.02 & 7.51 \\
\hline CSPP-eligible bond $=$ & 936 & 0.56 & 0.50 & 0.00 & 1.00 \\
\hline Inve & 936 & 0.61 & 0.49 & 0.00 & 1.00 \\
\hline Euro-denominated bond $=1$ & 936 & 1.00 & 0.00 & 1.00 & 1.00 \\
\hline Non-financial corporate bond $=1$ & 936 & 1.00 & 0.00 & 1.00 & 1.00 \\
\hline Eligible maturity at time of purchase $=1$ & 936 & 1.00 & 0.00 & 1.00 & 1.00 \\
\hline
\end{tabular}

Control group: ineligible EUR-denominated green financial bonds

$\begin{array}{llllll}\text { Yield to maturity } & 884 & 0.66 & 0.46 & 0.01 & 1.60 \\ \text { CSPP-eligible bond }=1 & 884 & 0.59 & 0.49 & 0.00 & 1.00 \\ \text { Investment grade bond =1 } & 884 & 0.94 & 0.24 & 0.00 & 1.00 \\ \text { Euro-denominated bond =1 } & 884 & 1.00 & 0.00 & 1.00 & 1.00 \\ \text { Non-financial corporate bond }=1 & 884 & 0.65 & 0.48 & 0.00 & 1.00 \\ \text { Eligible maturity at time of purchase }=1 & 884 & 1.00 & 0.00 & 1.00 & 1.00\end{array}$

Control group: quasi-eligible USD-denominated bonds

\begin{tabular}{|c|c|c|c|c|c|}
\hline Yield to maturity & 1077 & 2.83 & 2.91 & 0.11 & 11.38 \\
\hline CSPP-eligible bond $=1$ & 1077 & 0.48 & 0.50 & 0.00 & 1.00 \\
\hline Investment grade bond $=1$ & 1077 & 1.00 & 0.00 & 1.00 & 1.00 \\
\hline Euro-denominated bond $=1$ & 1077 & 0.48 & 0.50 & 0.00 & 1.00 \\
\hline Non-financial corporate bond $=1$ & 1077 & 1.00 & 0.00 & 1.00 & 1.00 \\
\hline Eligible maturity at time of purchase $=1$ & 1077 & 1.00 & 0.00 & 1.00 & 1.00 \\
\hline \multicolumn{6}{|c|}{ Control group: quasi-eligible SEK-denominated bonds } \\
\hline Yield to & 624 & 0.87 & 0.47 & 0.05 & 1.91 \\
\hline $\mathrm{CSPl}$ & 624 & 0.83 & 0.37 & 0.00 & 1.00 \\
\hline$d=1$ & 624 & 1.00 & 0.00 & 1.00 & 1.00 \\
\hline Euro-denominated bond $=1$ & 624 & 0.83 & 0.37 & 0.00 & 1.00 \\
\hline Non-financial c & 624 & 1.00 & 0.00 & 1.00 & 1.00 \\
\hline Eligible maturity at time of purchase $=1$ & 624 & 1.00 & 0.00 & 1.00 & 1.00 \\
\hline
\end{tabular}

PEPP

Control group: ineligible EUR-denominated green non-financial bonds

$\begin{array}{lccccc}\text { Yield to maturity } & 6570 & 1.67 & 2.85 & -0.08 & 13.60 \\ \text { PEPP-eligible bond }=1 & 6570 & 0.65 & 0.48 & 0.00 & 1.00 \\ \text { Investment grade bond }=1 & 6570 & 0.86 & 0.35 & 0.00 & 1.00 \\ \text { Euro-denominated bond }=1 & 6570 & 1.00 & 0.00 & 1.00 & 1.00 \\ \text { Non-financial corporate bond }=1 & 6570 & 1.00 & 0.00 & 1.00 & 1.00 \\ \text { Eligible maturity at time of purchase }=1 & 6570 & 0.94 & 0.23 & 0.00 & 1.00\end{array}$

Control group: ineligible EUR-denominated green financial bonds

\begin{tabular}{|c|c|c|c|c|c|}
\hline Yield to maturity & 8970 & 0.60 & 0.70 & -0.33 & 2.71 \\
\hline PEPP-eligible bond $=1$ & 8970 & 0.50 & 0.50 & 0.00 & 1.00 \\
\hline Investment grade bond $=1$ & 8970 & 0.98 & 0.14 & 0.00 & 1.00 \\
\hline Euro-denominated bond $=1$ & 8970 & 1.00 & 0.00 & 1.00 & 1.00 \\
\hline Non-financial corporate bond $=1$ & 8970 & 0.53 & 0.50 & 0.00 & 1.00 \\
\hline Eligible maturity at time of purchase $=1$ & 8970 & 0.98 & 0.13 & 0.00 & 1.00 \\
\hline \multicolumn{6}{|c|}{ Control group: quasi-eligible SEK-denominated bonds } \\
\hline Yield to maturity & 4928 & 0.83 & 0.77 & -0.08 & 2.91 \\
\hline PEPP-eligible bond $=1$ & 4928 & 0.87 & 0.34 & 0.00 & 1.00 \\
\hline Investment grade bond $=1$ & 4928 & 1.00 & 0.00 & 1.00 & 1.00 \\
\hline Euro-denominated bond $=1$ & 4928 & 0.87 & 0.34 & 0.00 & 1.00 \\
\hline Non-financial corporate bond $=1$ & 4928 & 1.00 & 0.00 & 1.00 & 1.00 \\
\hline Eligible maturity at time of purchase $=1$ & 4928 & 1.00 & 0.00 & 1.00 & 1.00 \\
\hline
\end{tabular}

Note: This table summarizes key variables used in the analysis below for the regression samples of green bonds issued in euro, U.S. dollars and Swedish crowns with non-zero yield observations. Source: 
Another potential threat to identification are spillovers from the treatment to the control group. For instance, the additional demand for eligible green bonds due to the CSPP and PEPP may encourage investors to increase their purchases of non-eligible green bonds also, for example by rebalancing their portfolios towards similar but ineligible green bonds. Increased demand for similar but ineligible bonds that are part of the control group will then increase prices and lower their yields. Such potential spillovers would bias our analysis against the expected direction of the treatment effect of the CSPP and PEPP on yields of eligible green bonds. Our regression analysis would thus estimate a lower bound effect.

\subsection{Empirical model}

As our baseline model, we estimate the following two-way fixed effects difference-indifference model over the period January 2016 - December 2016 for the evaluation of the CSPP and for January 2020 - October 2020 for the PEPP to capture the causal effect of being eligible under these programs on the bid yields of green corporate bonds,

$$
y_{i t}=\beta(\text { eligible } \cdot \text { post })_{i t}+\Gamma_{t}+\mu_{i}+\epsilon_{i t} \text {; }
$$

where $y_{i t}$ is the outcome of interest, namely the average bid yield to maturity of bond $i$ in week $t$. The policy indicator $($ eligible $\cdot$ post) $i t$ is a dummy variable that switches from 0 to 1 for eligible bonds after the announcement of the CSPP during the week of March 10, 2016, and after the announcement of the PEPP during the week of March 12, 2020. As the policy indicator is credibly exogenous, this parsimonious specification provides a useful baseline estimation of the treatment effect of interest. The parameter $\beta$ captures the treatment effect of being eligible for the CSPP/PEPP on eligible green bonds. Given that not all eligible green bonds are actually bought by the ECB, $\beta$ captures an intention to treat effect on the treated. As a fraction of eligible bonds do not end up being purchased, our estimate of the effectiveness of the CSPP/PEPP with respect to green bonds represents a lower bound of the average treatment effect on the treated.

Information kindly provided by the ECB on the bonds actually bought directly after the start of the CSPP show that, in the beginning of the CSPP, the majority of (the small number of) eligible green bonds were also purchased. In terms of volumes, both under the CSPP and PEPP, about $20 \%$ of the universe of the outstanding amount of eligible green 
bonds were actually bought by the ECB on average between 2018 and 202014 Therefore, the more conservative intention-to-treat interpretation of $\beta$ may be more appropriate.

$\Gamma_{t}$ are week fixed effects, while $\mu_{i}$ are bond fixed effects. In the two-way fixed effects model with week and bond fixed effects, the subcomponents of the policy variable, namely treated $_{i}$ and post $_{t}$, are absorbed. In order to gauge the individual effects of the subcomponents post and eligible, in addition to our baseline specification described in equation (1), we also estimate a less restrictive model without fixed effects. Further, to control for time-varying factors at the country and at the sector level, we add country-by-month as well as sector-by-month fixed effects to the specification in (1). In all specifications, we cluster standard errors at the bond level to robustify against serial correlation in the outcome (Bertrand et al. 2004).

As a second step in our empirical analysis, we disaggregate the policy indicator over time in an event-study set-up. We estimate the following equation:

$$
y_{i t}=\sum_{m=-p}^{q} \rho_{m}(\text { treated } \cdot \text { post })_{i, t=0+m}+\Gamma_{t}+\mu_{i}+\epsilon_{i t} \text {; }
$$

where $y_{i t}$ is, again, the average bid yield to maturity of bond $i$ in week $t$. In contrast to equation (1) the policy indicator is disaggregated into $p$ pre-treatment and $q$ posttreatment periods, with the last pre-treatment period left out as the baseline period. $t=0$ indicates the start of the post-treatment period. Point estimates for coefficients during the pre-treatment period insignificantly different from zero indicate that pre-treatment trends are parallel. The behavior of point estimates during the post-treatment period provides evidence about the persistence of the treatment effect. As in equation (1), $\Gamma_{t}$ are week fixed effects and $\mu_{i}$ are bond fixed effects; standard errors are clustered at the bond level.

We estimate both models using different samples. When defining treatment and control groups, we impose the minimum balancing condition that each bond must be observed in at least one pre-treatment period 15 While the group of green bonds eligible for the CSPP and PEPP always remains the same in the respective sample, we vary the subsample of non-eligible bonds to account for different control groups.

Table 2 presents summary statistics separately for all regression samples, that is, in-

\footnotetext{
${ }^{14}$ see Figure 9 in a 2020 speech by Isabel Schnabel at

https://www.ecb.europa.eu/press/key/date/2020/html/ecb.sp200717 1556b0f988.en.html and the ECB Economic Bulletin, Issue 7/2018 https://www.ecb.europa.eu/pub/economicbulletin/focus/2018/html/ecb.ebbox201807,1.en.html

${ }^{15}$ Our results are robust to not imposing this balancing condition.
} 
cluding CSPP-eligible green bonds and four different control groups for the CSPP, and PEPP-eligible corporate green bonds with three different control groups for the PEPP. In all cases, the number of eligible green bonds is close to or above $50 \%$ of the included observations. Depending on the control groups, average yields differ quite substantially between 0.66 and $2.83 \%$ for the CSPP-sample (2016) and between 0.6 and $1.67 \%$ for the PEPP-sample (2020).

For the evaluation of the CSPP, first, we compare eligible green bonds to green bonds, issued in euro, by non-financial corporations that are ineligible under the CSPP, e.g. as they are rated below investment grade (see Table 2, top section). Thus, we compare the performance of corporate green bonds, CSPP-eligible and not, when using this sample. As a second control group, we consider ineligible green bonds issued by financial corporations. The idea behind this alternative control group is to compare the evolution of "treated" green bond yields to a group of green corporate bonds that is more similar to eligible bonds, e.g. in terms of ratings. Table 2, second section, reveals that with this control group, a higher share of bonds is rated investment grade. The third control group consists of corporate green bonds issued in U.S. dollars that fulfill all other CSPP-eligibility criteria apart from the currency of issue. We call this group "quasi-eligible" green bonds. The advantage of this control group is that the bonds have similar characteristics, e.g. in terms of rating categories, remaining maturities and sector of the issuer, and that a relatively large number of bond observations is available. Finally, we compare CSPP-eligible green corporate bonds to "quasi-eligible" green bonds from another important European green bond market, namely green bonds issued in Swedish crowns.

For the PEPP, we consider a parallel set of control groups as for the CSPP (see Table 2, bottom part). However, the Fed announced a corporate sector purchase program on March 15, 2020, i.e. during the same days as the ECB announced increased corporate sector purchases under the PEPP (Figure 1). Thus, due to these concurrent policy events, we refrain from using U.S. dollar-issued quasi-eligible bonds for the evaluation of the effects of the PEPP on green bond yields. For green bonds denominated in Swedish crowns, though, there are no concurrent policy events close to the announcement of the PEPP. The Riksbank started buying corporate bonds in response to the Covid-pandemic in September 2020 only. Hence, an impact evaluation of the PEPP on eligible green bond yields in comparison to corporate green bonds denominated in Swedish crowns seems reasonable, especially for the period before September. 


\section{Results}

In this section we first consider descriptively whether the parallel trends assumption appears plausible for the different control groups (Section 5.1). We then present our baseline estimation of the causal effect of being eligible on the yields of eligible green bonds for the CSPP (Section 5.2.1) and for the PEPP (Section 5.2.2), respectively. In Section 5.3 we implement an event study design to formally evaluate the validity of parallel pre-treatment trends as well as to analyze the persistence of treatment effects, both for the CSPP (Section 5.3.1) and for the PEPP (Section 5.3.2).

\subsection{Parallel trends}

We inspect parallel trends for our seven estimation samples, four for the CSPP (Figure 4) and three for the PEPP (Figure 5). In each panel, the vertical red line indicates the week when each program was announced (CSPP on March 10, 2016, and PEPP on March 12, 2020), while the blue line marks their implementation (June 8, 2016 for CSPP, and March 26 for PEPP). The delay between announcement and implementation was much more pronounced for the CSPP than for the PEPP.

Figure 4(a) shows average bid yields to maturity of CSPP-eligible green bonds and EUR-denominated ineligible green bonds issued by non-financial corporations. During the weeks after both the announcement and the implementation date, the average yield of eligible green bonds declines by more than $20 \mathrm{bp}$. The yields of green bonds not eligible for the CSPP are much higher than those of eligible ones, among others due to the inferior ratings and hence higher risk premia, and vary more strongly. Qualitatively, they appear to move in parallel.

The case for parallel trends is even more clear-cut for ineligible EUR-denominated green bonds issued by financial institutions (Figure 4(b)]. Pre-treatment yields appear to move in parallel, with a convergence after both announcement and implementation of CSPP, and a renewed divergence toward the end of the sample period.

We next turn to our control groups drawn from non-euro corporate green bonds: quasieligible U.S. dollar and Swedish crown-denominated green bonds. Quasi-eligible bonds are corporate bonds denominated in currencies other than EUR but that meet all other eligibility criteria (for a detailed explanation see Section 3). Figure 4(c) depicts average yields of CSPP-eligible green bonds and U.S. dollar-denominated quasi-eligible green bonds. When 


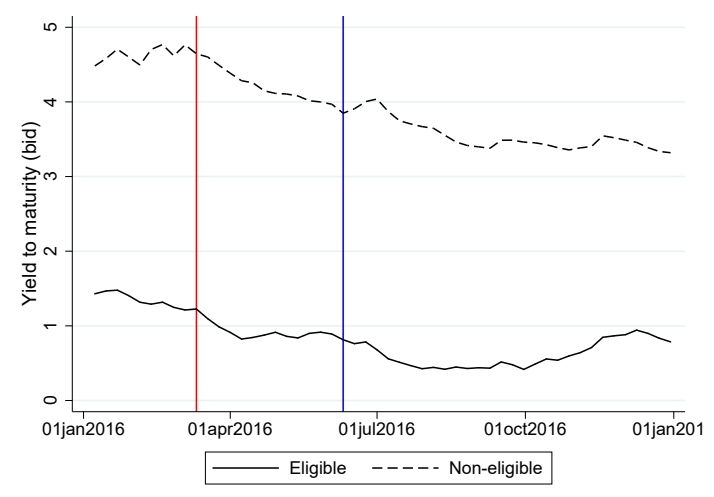

(a) Ineligible non-financials (EUR)

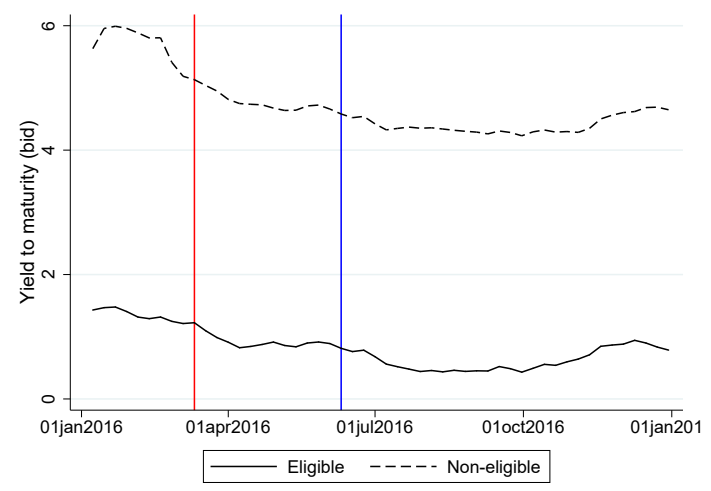

(c) Quasi-eligibles (USD)

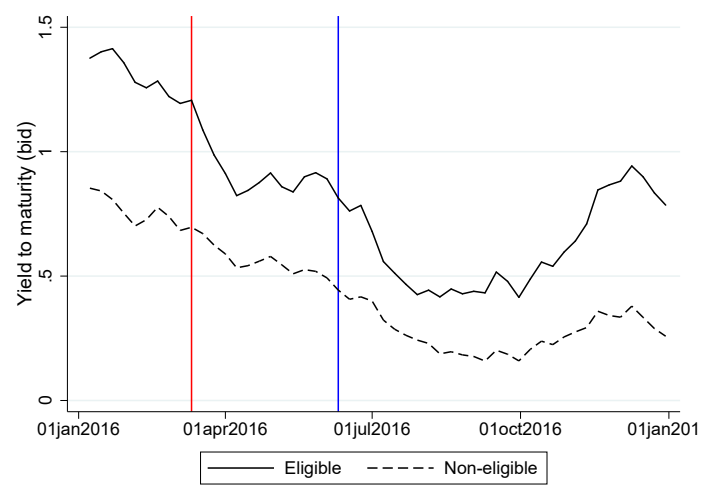

(b) Ineligible financials (EUR)

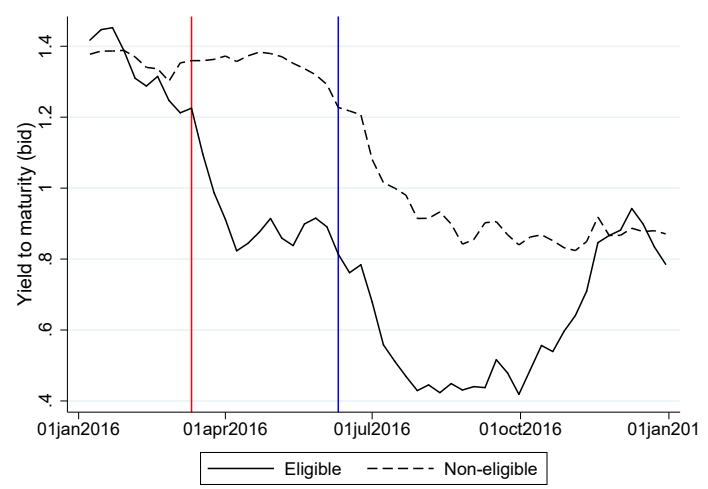

(d) Quasi-eligibles (SEK)

Figure 4: Yields to maturity, CSPP sample

Note: The graphs depict bid yields to maturity for the treatment group of CSPP-eligible corporate green bonds and for different control groups. The red line indicates the announcement of CSPP, the blue line its implementation. Sample sizes with eligible green bonds and: ineligible non-financial (EUR) control group (Panel a) - 936 observations; ineligible financial (EUR) control group (Panel b) - 884 observations; quasi-eligible USD control group (Panel c) - 1,077 observations; quasi-eligible SEK control group (Panel d) - 624 observations.

the CSPP is announced, the average yield of U.S. dollar-denominated quasi-eligible green bonds is in the region of $5 \%$. We observe a decrease in their average yields starting before the announcement of the CSPP. However, during the remainder of the sample period, average yields of our "treated" and of quasi-eligible USD-denominated green bonds move rather in parallel.

In the beginning of the sample period, the yields of Swedish crown-denominated quasieligible green bonds are very similar to those in the treatment group (Figure $4(\mathrm{c})$ ) in terms of levels. Yet, they diverge sharply after the announcement of the CSPP with CSPPeligible green bonds dropping significantly while after the announcement while Swedish crown-denominated quasi-eligible bond yields remain more or less constant. The yield differential remains until a renewed convergence at the end of the sample period. 
The descriptive analysis of yields around the announcement of the CSPP suggests that the parallel trends assumption is broadly plausible for the control groups of corporate green bonds. However, note that due to small sample sizes the averages vary substantially, so that the formal analysis of pre-treatment trends in Section 5.3 will provide final confirmation.

The descriptive case is more clear-cut for the PEPP (Figure 5). Here, we conduct an analogous exercise, with the difference that quasi-eligible U.S. dollar-denominated green bonds are excluded due to concurrent asset purchasing policy measures by the Fed that began virtually simultaneously (see Section 2). Therefore, three control groups remain: ineligible euro-denominated green bonds issued by non-financial corporations (Figure $5(\mathrm{a})$ ), ineligible EUR-denominated green bonds issued by financial institutions (Figure 5(b)] and quasi-eligible Swedish crown-denominated corporate green bonds (Figure 5(c)] .

Pre-treatment average yields in all three control groups move in parallel with average yields in the treatment group. In all cases, yields increase sharply just prior to and immediately after the announcement of the PEPP. This reflects the severity of the initial shock of the uncertainty about the Covid-19 pandemic and its associated lockdowns, several of which were announced around the same time as the announcement of PEPP. Average yields behave differently after the start of the post-treatment period. The difference in average yields between the treatment group and ineligible EUR-denominated non-financial green bonds remains roughly stable, with a difference of about 2.5-3 percentage points. In contrast, yields of eligible green bonds and bonds issued by financial institutions diverge somewhat, while yields of Swedish crown-denominated bonds strongly diverge after the announcement of the PEPP and later converge again.

The descriptive analysis of yields before and after the announcement of the PEPP suggests that the parallel trends assumption is plausible.

\subsection{Main results}

\subsubsection{CSPP}

We first consider the treatment effect of the announcement of the CSPP on yields of eligible green bonds, compared to EUR-denominated green corporate bonds ineligible for the CSPP. We divide the group of EUR-denominated corporate bonds into those issued by non-financial corporate issuers (Table 3, columns (1)-(4)) and financial institutions (Table 3. columns (5)-(8)). 

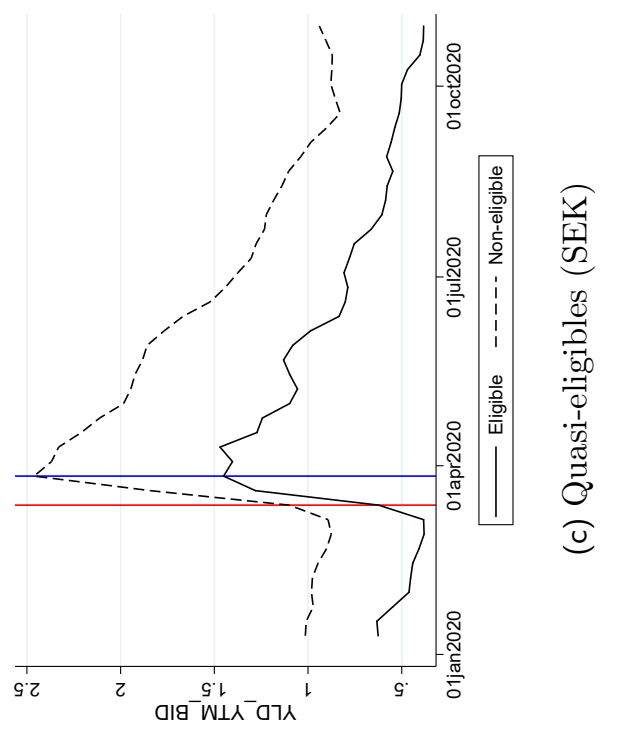

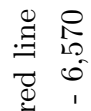

कृ

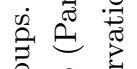

क्षे :

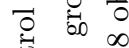

हैं

च्ञ

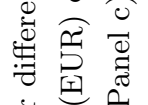

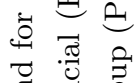

चี

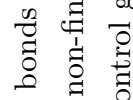

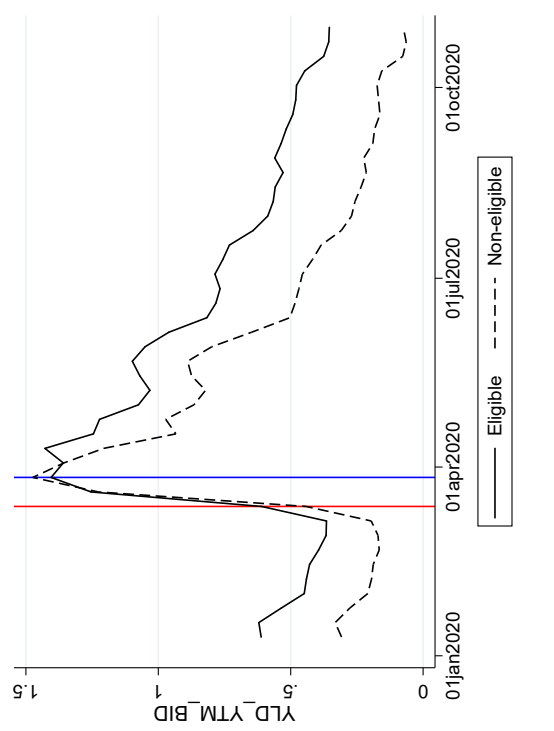

월 $\frac{0}{2}$ 范

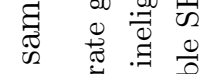

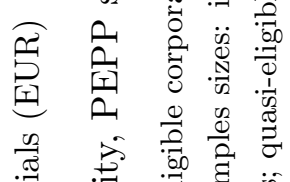

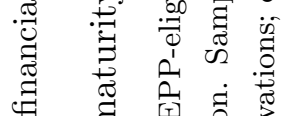

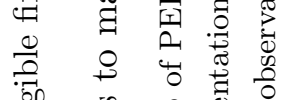

焉

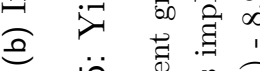

เก

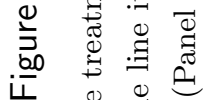

용

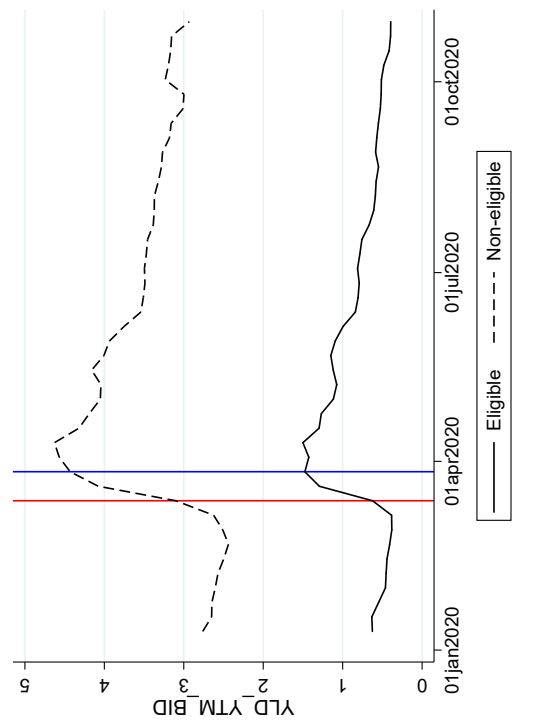

过

宅

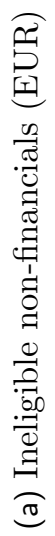

:

올 존

娄这

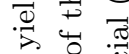

궁

듬

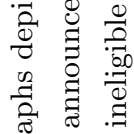

का

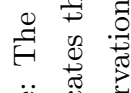

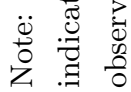


For the group of bonds issued by non-financial firms, we find no effect of the CSPPannouncement on yields for the simpler specifications without fixed effects, the standard two-way fixed effects model or when controlling, in addition, for country-by-month fixed effects. The insignificant effect could indicate that there are no market distortions in response to the CSPP-announcement between eligible and ineligible green bonds (see, e.g. the discussion by Zaghini (2019)). Yet, it can also mask counteracting effects across the post-treatment period or indicate portfolio rebalancing effects towards the control group considered here.

In line with the descriptive evidence presented in the previous section, the estimation results in column (1) indicate that eligible green bonds have a much lower yield compared to ineligible bonds in this sample. Moreover, yields on all green bonds are on average significantly lower after the CSPP-announcement than before, as indicated by the negative and significant effect of the post-dummy. Only in the specification including sector-by-month fixed effects (column (4)) do we find a statistically significant and negative effect of the announcement of corporate bond purchases by the ECB. In this case, the results suggest that the CSPP reduced the yields of eligible green bonds by 18 basis points compared to non-eligible bonds issued by non-financial corporations. A clearer and more robust picture emerges when using green bonds issued by financial institutions as a control group. We find a statistically significant impact of the CSPP announcement, which is stable across all four specifications. According to our estimations, the announcement of the CSPP decreased the yield to maturity of eligible green bonds by 20-29 basis points relative to the yield of the control group. These finding are broadly in line with the literature studying effects of the CSPP on yields of the whole eligible corporate bond universe that consists mainly of conventional bonds (Todorov, 2020, De Santis et al., 2018; De Santis and Zaghini, 2019, Zaghini, 2019).

Hence, it appears that the ECB's announcement to buy corporate bonds reduces yields of eligible green bonds, i.e. investment grade green bonds of non-financial corporations more than for ineligible bonds. Intuitively, this may be due to the fact that investors took some time to rebalance their portfolios towards similar bonds, such that there is not much additional demand for the ineligible green bonds issued by financial institutions during our sample period that could reduce yields in the control group, too. As shown by the event-study results presented below (Figure 6(b)), after several months, yield differences between treatment and control group start to become smaller. In line with the findings 
by Zaghini (2019), this may point to a portfolio rebalancing effects that start to unfold after several month.

Our results are similar when using quasi-eligible U.S. dollar-denominated (Table 4. columns (1)-(4)) and Swedish crown-denominated green bonds (Table 4 columns (5)(8)) as control groups. Our results reveal that in response to the CSPP-announcement, yields of eligible green bonds fall by 23 bp compared to U.S. dollar-denominated green bonds. Relative to green bonds denominated in Swedish crowns, our analysis suggests an impact of the CSPP of up to $33 \mathrm{bp}$. We therefore conclude that the CSPP introduced a significant wedge in financing conditions both within the euro area and compared to non-euro currencies. However, the wedge is of varying relative size.

While the magnitude of the treatment effect in terms of basis points is of similar size across the four control groups, the impact of the CSPP on financing conditions for issuers of eligible green bonds vis-à-vis the various control groups is very different due to differences in average yields between the control groups and the treatment group. When evaluating the differential effect relative to the average difference between the yields of eligible bonds and ineligible bonds issued by non-financial firms (-300 bp), the CSPP effect only amounts to $6 \%$. For the difference in yields between eligible bonds and ineligible bonds of financial firms (40 bp), the impact of the CSPP corresponds to $50-75 \%$ of this difference though.

\subsubsection{PEPP}

We next consider the impact of the announcement of the PEPP on the yields of eligible green bonds, compared to three control groups already used in our analysis of the impact of the CSPP above. Unfortunately, the group of quasi-eligible U.S. dollar-denominated green bonds cannot be considered due to a concurrent asset purchasing policy by the U.S. Fed (Figure 1). We note that due to the severe and asymmetric shock due to the first wave of the Covid-19-pandemic and the subsequent lockdowns and other policy measures mostly taken at the country level, it is crucial to control for country-time effects during this sample period. This is why the specification controlling for country-by-month fixed effects is our preferred specification when analyzing the impact of the PEPP on bond yields.

Overall, as discussed descriptively in Section 5.1 after a strong increase in yields before the announcement of the PEPP, yields decreased again after the implementation of the PEPP. Table 5 presents our estimates for the control groups of euro-denominated corpo- 


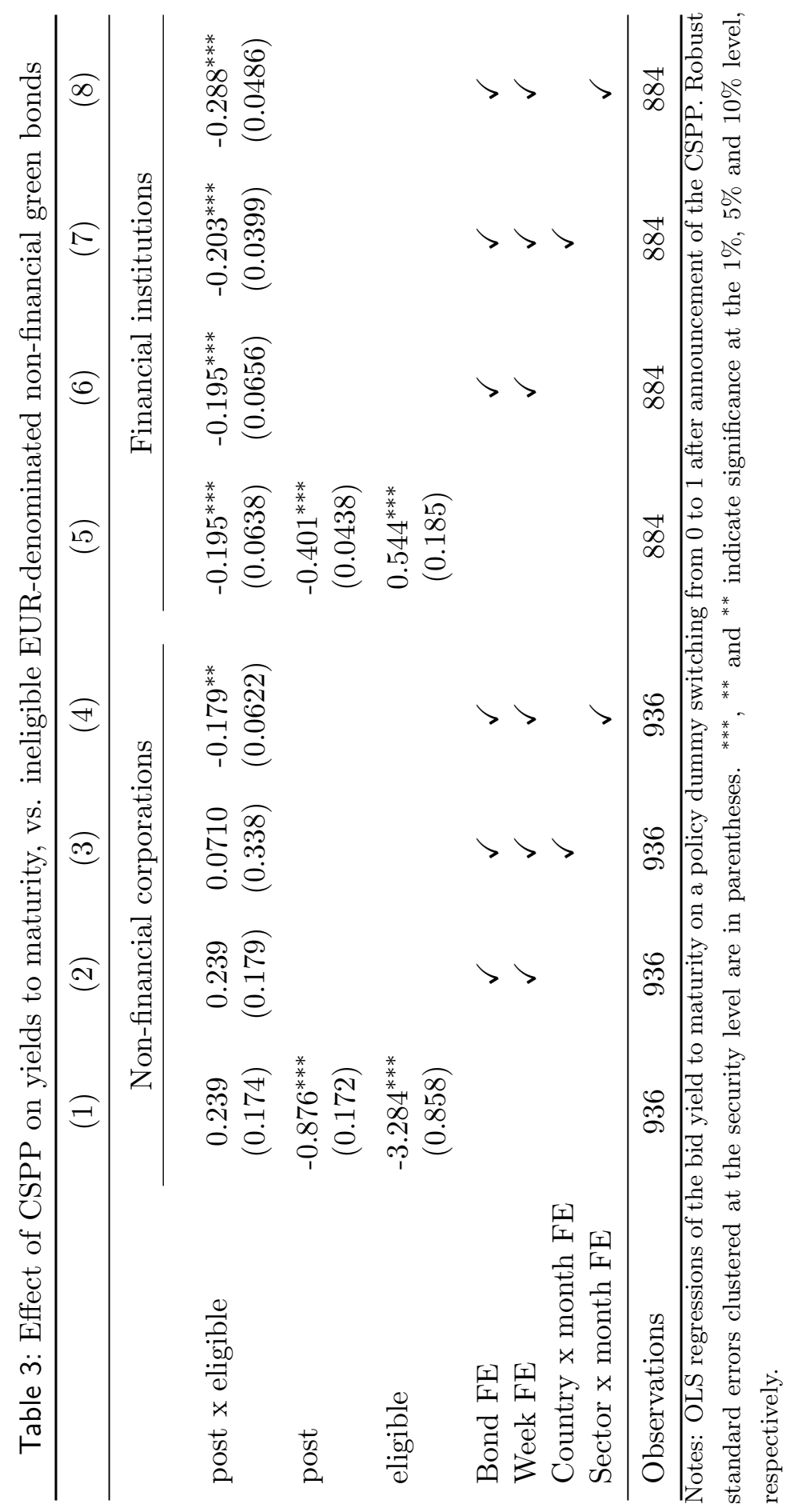




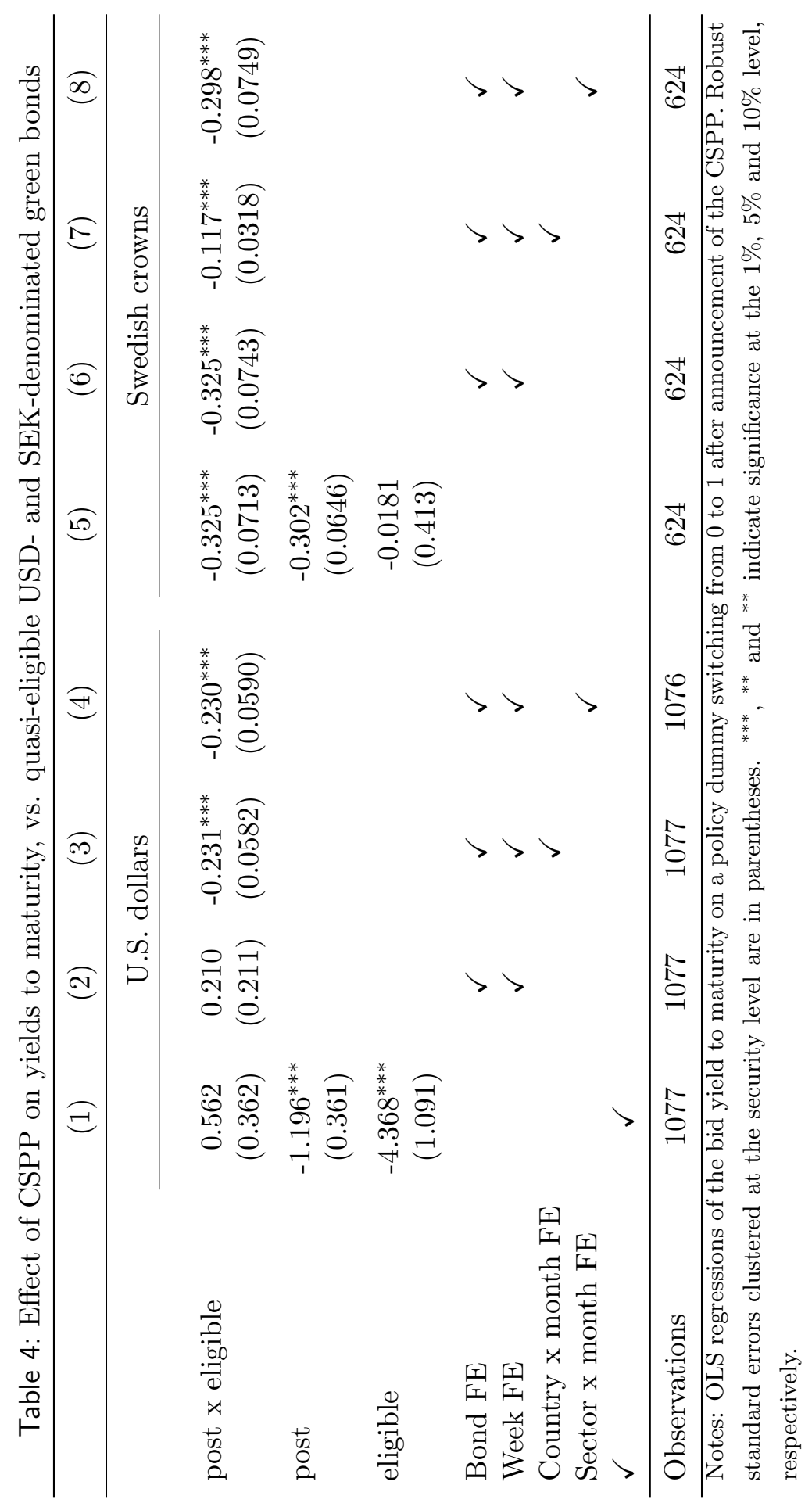


rate bonds issued by non-financial corporations (Table 5 , columns (1)-(4)) and financial institutions (Table 5 , columns (5)-(8)). We find a both statistically and economically highly significant effect of the PEPP for the control group of ineligible corporate green bonds. Our estimates suggest that yields of eligible green bonds declined by up to $135 \mathrm{bp}$ during the sample period compared to ineligible green bonds issued by non-financial corporations (column (3)). The stronger effect of the PEPP compared to the CSPP for this control group may suggests that investors were far more averse to holding below-investment grade (green) bonds than they were when the CSPP was announced, suggestion a stronger safety premium channel. Thus, portfolio rebalancing may have been much weaker under the PEPP, especially when considering below-investment grade green bonds as a control group. This may be due to the severity and uncertainty of the Covid-19 shock and the associated lockdown measures on bond markets.

In contrast, the PEPP did not have a significant average treatment effect on eligible green bonds compared to ineligible green bonds issued by financial institutions - which may support the idea that investors were searching for alternative investments of similar (low-risk) characteristics and green bonds of financial firms mostly being investment grade (Table 2). As shown in Section 5.3, the difference compared to ineligible bonds issued by non-financial corporations is explained by the speed of adjustment. While the initial shock on yields was even stronger for bonds issued by financial institutions, their yields converged to those of PEPP-eligible green corporate bonds rapidly. In contrast, the yields of non-eligible bonds issued by non-financial corporations only converge toward the end of our sample period, leading to a large negative average treatment effect for this control group.

Finally, we consider the effect of the PEPP on the yields of Swedish crowns-issued quasi-eligible green bonds (Table 6). We obtain that the PEPP decreased the yields of eligible green bonds by 15 basis points relative to similar bonds denominated in Swedish crowns in our preferred specification (column (3)). Financing conditions of issuers of green bonds therefore improved compared to those issuing in Swedish crowns.

\subsection{Event study design}

\subsubsection{CSPP}

This section presents the results using the event study design (Equation 2). The purpose of this exercise is to investigate the evolution of treatment effects on yields pre- and post- 


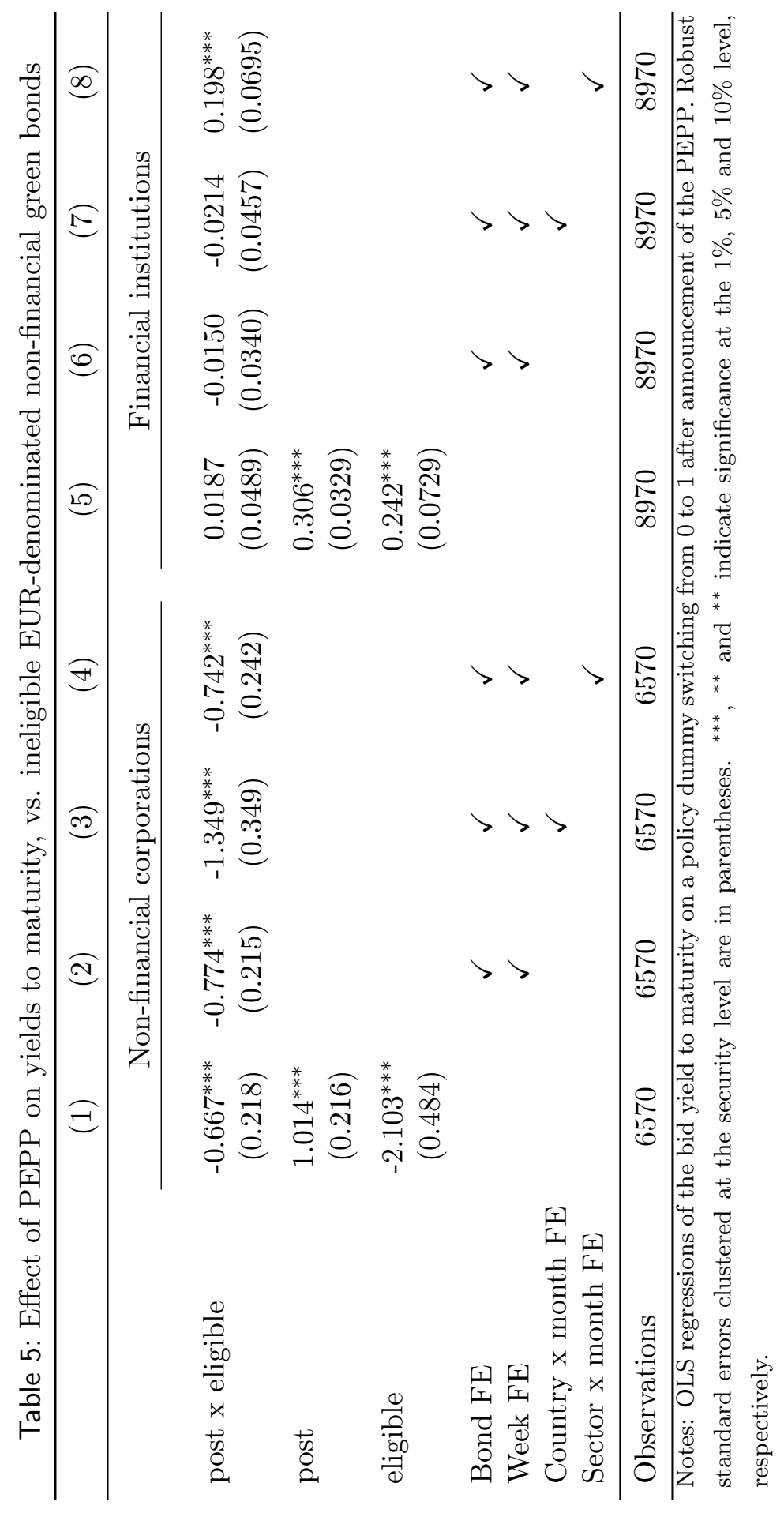


Table 6: Effect of PEPP on yields to maturity, vs. quasi-eligible SEK-denominated green bonds

\begin{tabular}{lcccc}
\hline & $(1)$ & $(2)$ & $(3)$ & $(4)$ \\
\hline post x eligible & $-0.164^{* *}$ & $-0.154^{* *}$ & $-0.150^{* * *}$ & 0.0193 \\
& $(0.0779)$ & $(0.0713)$ & $(0.0501)$ & $(0.0935)$ \\
post & $0.499^{* * *}$ & & & \\
& $(0.0715)$ & & & \\
eligible & $-0.470^{* * *}$ & & & \\
& $(0.126)$ & & & \\
Bond FE & & $\checkmark$ & $\checkmark$ & $\checkmark$ \\
Week FE & & $\checkmark$ & $\checkmark$ & $\checkmark$ \\
Country x month FE & & & $\checkmark$ & \\
Sector x month FE & & & & $\checkmark$ \\
\hline Observations & 4928 & 4928 & 4928 & 4928
\end{tabular}

Notes: OLS regressions of the bid yield to maturity on a policy dummy switching from 0 to 1 after announcement of the PEPP. Robust standard errors clustered at the security level are in parentheses. ${ }^{* * *}$, ${ }^{* *}$ and ${ }^{* *}$ indicate significance at the $1 \%, 5 \%$ and $10 \%$ level, respectively.

treatment in greater detail by disentangling the effects across time. Pre-treatment, this disaggregation allows us to investigate the validity of the parallel trends assumption, while post-treatment, we can evaluate the persistence of treatment effects.

Figure 6 depicts point estimates and $95 \%$ confidence bands for the two-way fixed effects model (e.g. Table 3, column (3)) for each of the four control groups. Note that while the estimates are obtained using the full sample period covering the entire year 2016, for better comparability with the results for the PEPP the graphs show point estimates and confidence bands up to 30 week after the announcement of the CSPP. Pre-treatment trends coefficients move in parallel for all four control groups, while post-treatment dynamics differ. For the group of non-eligible euro-denominated corporates (Figure 6(a)), the treatment effect dynamics are insignificant, in line with our finding in Table 3, column (3).

In contrast, Figure 6(b) shows that for euro-denominated bonds issued by financial institutions the effect of the CSPP on yields of eligible green bonds is persistent. The estimated treatment effect is significantly negative in most periods throughout the sample period, suggesting that financing conditions for issuers of eligible green bonds remain favorable due to the CSPP, compared to bonds issued by financial corporations.

The event study using U.S. dollar-denominated quasi-eligible green bonds as the comparison group (Figure 6(c) shows that post-treatment coefficients in the basic two-way fixed effects model are not significantly different from zero throughout the post-treatment 
period. This confirms our result for this group from the baseline regression analysis, which had shown that the estimate of the treatment effect only turns negative once we additionally control for country-by-year effects or sector-by-year effects.

Finally, the control group of Swedish crown-denominated quasi-eligible green bonds offers clear insights on treatment effect dynamics for this comparison group. Similarly to our result for ineligible euro-denominated bonds issued by financial institutions, the treatment effect on yields of eligible green bonds remains negative and significant for the majority of the post-treatment period. This finding suggests that the CSPP persistently improved financing conditions for eligible green bonds compared to similar Swedish crowndenominated bonds, other than the currency of issue.

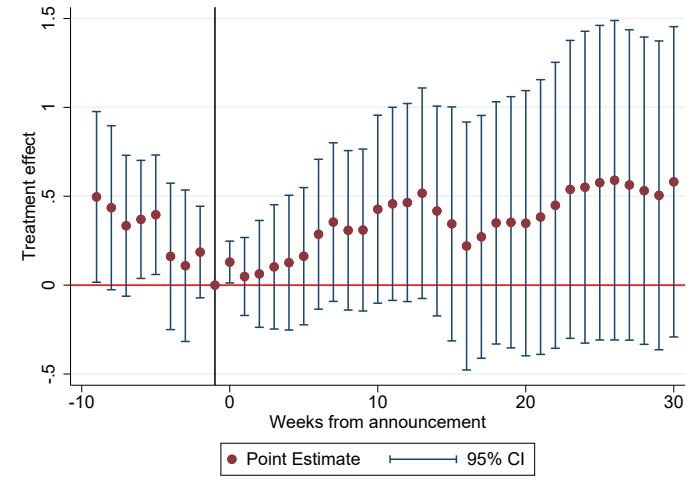

(a) Ineligible non-financials (EUR)

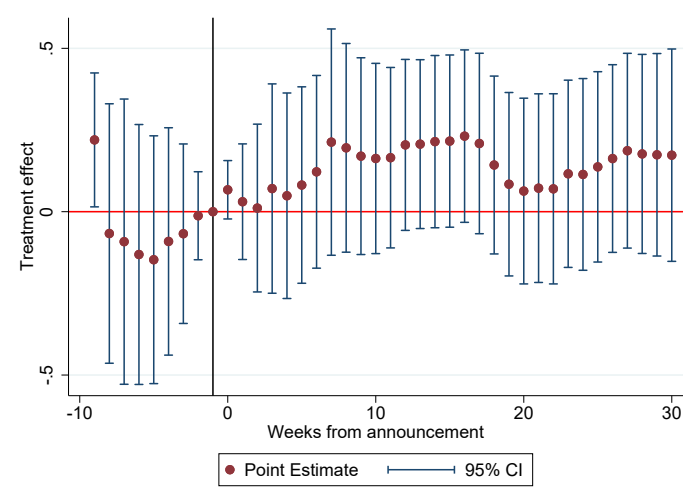

(c) Quasi-eligibles (USD)

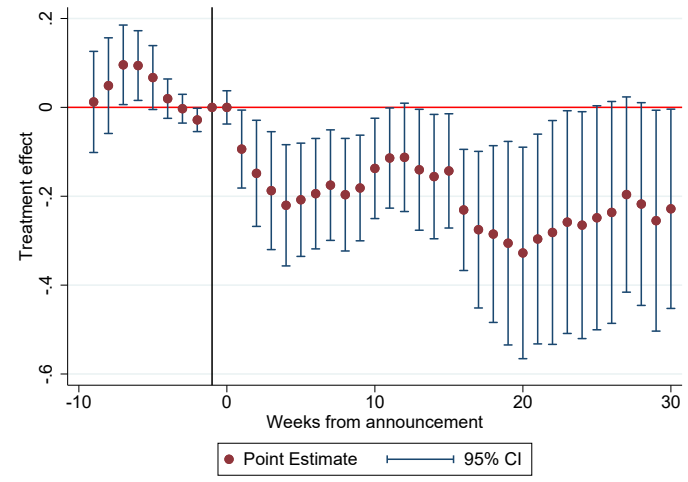

(b) Ineligible financials (EUR)

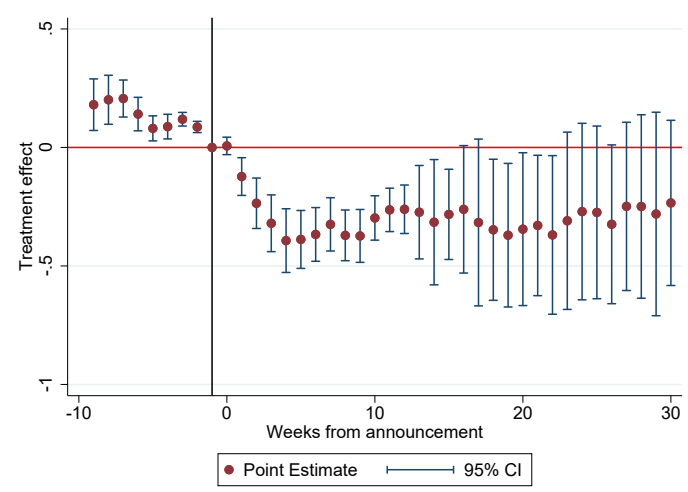

(d) Quasi-eligibles (SEK)

Figure 6: Effect of CSPP on yields to maturity

Note: OLS regressions of bid yields to maturity on a temporally disaggregated policy indicator for an event window of 9 weeks before and 43 weeks after the announcement of the CSPP. For consistency with PEPP results 30 post-treatment periods are depicted. The graphs depict point estimates and $95 \%$ confidence intervals using robust standard errors clustered at the security level. Samples sizes: ineligible euro-denominated non-financial corporates control group (Panel a) - 936 observations; ineligible euro-denominated financials control group (Panel b) - 884 observations; quasieligible U.S. dollar-denominated control group (Panel c) - 1,077 observations; quasi-eligible Swedish crown-denominated control group (Panel d) - 624 observations. 


\subsubsection{PEPP}

We now analyze pre-treatment trends and post-treatment dynamics for the PEPP (Figure 7). As in our main analysis of the effects of PEPP on yields, we leave out the comparison group of U.S. dollar-denomiated green bonds due to a concurrent asset purchasing policy by the Fed. Again, for all three cases estimates of the pre-treatment policy indicator are in line with the parallel trends assumption.

For the comparison group of non-eligible euro-denominated bonds issued by nonfinancial corporates we confirm the strong negative treatment effect of the PEPP on the yields of eligible bonds found in the main analysis (Table 5). Additionally, Figure 7(a) shows that the divergence in yields is persistent, with negative point estimates for the policy indicator throughout the post-treatment period. Financing conditions for eligible green bonds therefore permanently improved compared to those of ineligible ones. As the difference in eligibility is mostly due to being rated investment grade, we conclude that investment-grade green bonds permanently benefit from the PEPP, compared to lowerrated bonds.

We next consider the treatment effect dynamics for the comparison group of eurodenominated bonds issued by financial institutions (Figure 7(b) . Here, the PEPP strongly lowered the yields of eligible bonds in the short run. However, about one month after the announcement of the PEPP the differential in yields converges back to zero. The lack of a persistent effect for this case may be due to the much higher share of investment-grade bonds in this comparison group.

As the final step in our analysis of treatment effect dynamics we revisit the control group of quasi-eligible Swedish crown-issued green bonds. As in the other cases, the PEPP had a strong negative effect of the yields of eligible green bonds in the short term of more than 40 basis points. In terms of persistence the group of Swedish crowndenominated bonds presents an intermediate case between the two euro-denominated comparison groups. Yields converge after about four months, faster than for euro-denominated bonds issued by corporates and more slowly than for euro-denominated bonds issued by financials. We conclude that the PEPP improved financing conditions of eligible green bonds compared to Swedish crown-issued bonds, but this advantage dissipated in the medium term. 


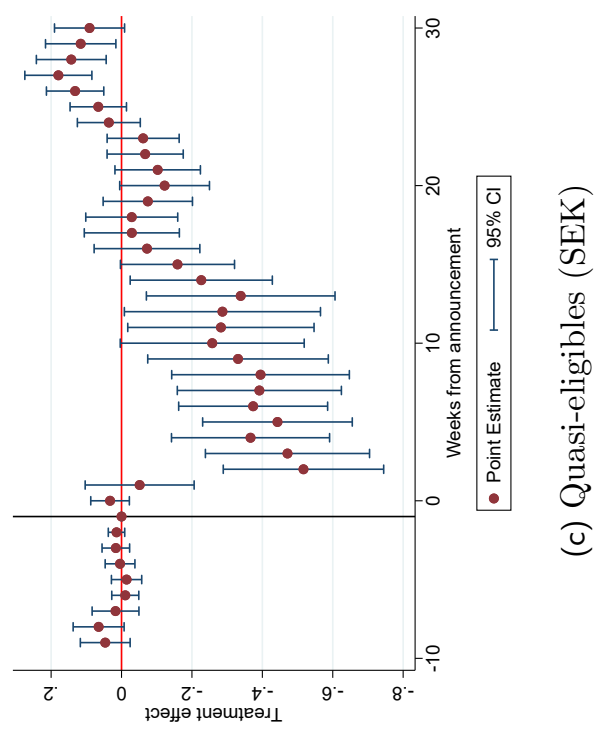

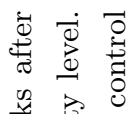

용

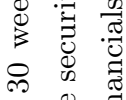

맇

ส

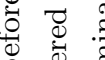

0

$\Phi$ U

○

पे

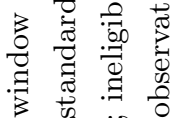

艺

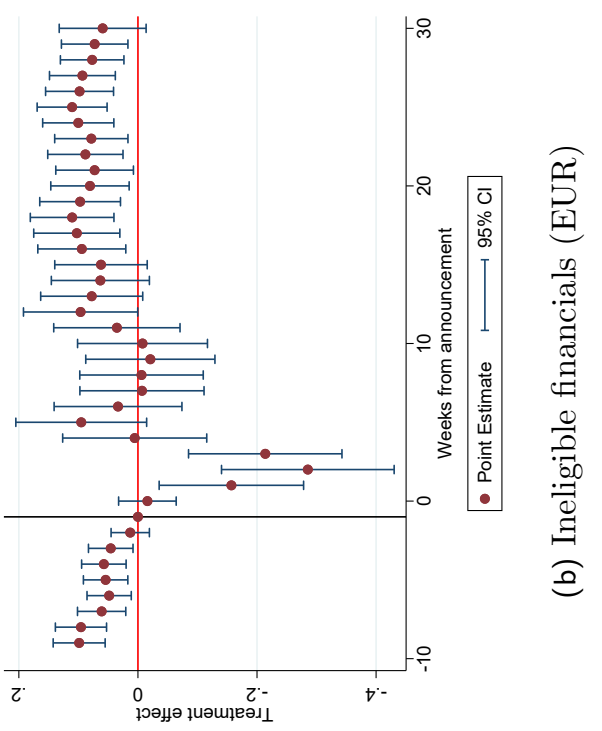

B.

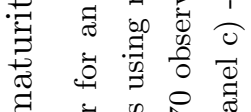

घ

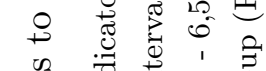

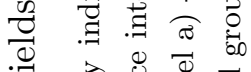

沗 总

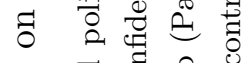

ค ग

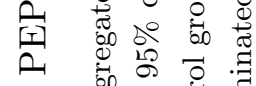

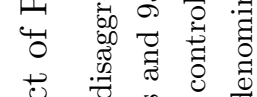

过

기류.

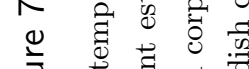

苛

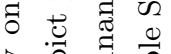

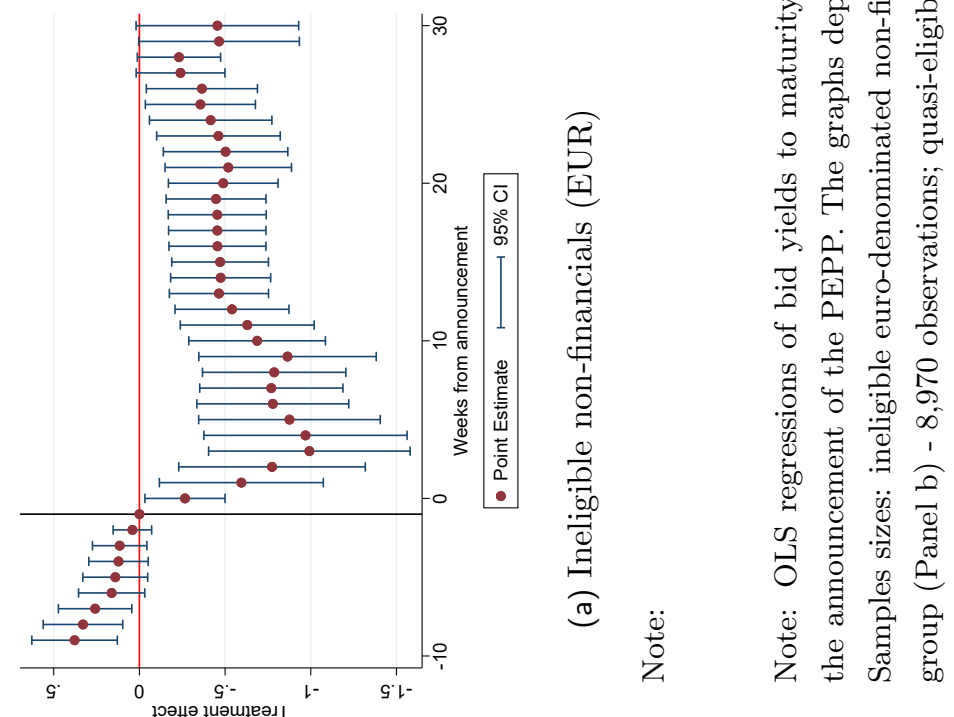




\section{Conclusion}

In this paper, we identify the causal effect of the ECB's corporate sector purchases under the CSPP and PEPP on the yields of green bonds. In a first step, we investigate whether and how the yields of green bonds that are eligible under these programs respond to the announcement of this program relative to ineligible euro-denominated green bonds, e.g. corporate bonds rated below investment grade or bonds issued by financial corporations. Second, we examine whether eligible corporate green bonds are affected compared to bonds issued in other currencies, namely the U.S. dollars and Swedish crowns.

The empirical analysis yields three main results. First, the yields of eligible green bonds significantly decline after the announcement of the ECB's corporate bond purchases both under the CSPP and PEPP relative to the yields of ineligible green bonds. Hence, additional demand via asset purchase programs improved financing conditions for eligible green corporate bonds. Second, the effects of both programs are heterogeneous. For the CSPP, yields of eligible green bonds decreased between 18 and $33 \mathrm{bp}$ compared to different control groups. Regarding the relative size of this improvement in financing conditions, our findings are in line with the findings on the effects of the CSPP on the whole universe of eligible corporate bonds. Yield differences after the introduction of the PEPP are even larger, up to $135 \mathrm{bp}$ compared to ineligible euro-denominated green corporate bonds. Results for sub-investment grade bonds differ greatly between the two asset purchase programs. The finding that the CSPP did not have a clear effect on yields of eligible green corporate bonds compared to ineligible euro-denominated green bonds issued by non-financial firms suggests that the latter bonds also benefited from the program at that time, potentially due to portfolio rebalancing effects. In case of the PEPP, yields of eligible green corporate bonds declined very strongly compared to yields of non-eligible euro-denominated green bonds issued by non-financial firms. This result suggests that investors were more hesitant to rebalance their portfolios towards non-investment grade bonds, possibly due to general economic concerns and stronger preferences for safe assets in response to the start of the Covid-pandemic. Third, in some cases these effects persist for several months after these exogenous policy events.

Regarding policy implications, our analysis is of clear relevance in several dimensions. First, we show that ECB corporate bond purchases were effective at improving financing conditions for issuers of eligible green assets in this increasingly important market seg- 
ment. It has also made the euro area more attractive as a location of issuance of green bonds. Second, the analysis informs the debate on a possible role of monetary policy for a transition towards a low-carbon economy. One such role would be to stimulate green investment through asset purchase programs. Third, our results show that the improved financing conditions for green bonds may make it more attractive for firms to finance investments via green bonds that are eligible for the asset purchase program, as opposed to other forms of financing. 


\section{References}

Abidi, Nordine and Ixart Miquel-Flores (2018) "Who Benefits from the Corporate QE? A Regression Discontinuity Design Approach," SSRN Scholarly Paper ID 2914911, Social Science Research Network, Rochester, NY, 10.2139/ssrn.2914911.

Albuquerque, Rui, Yrjö Koskinen, and Chendi Zhang (2019) "Corporate social responsibility and firm risk: Theory and empirical evidence," Management Science, 65 (10), $4451-4469$.

Baker, Malcolm, Daniel Bergstresser, George Serafeim, and Jeffrey Wurgler (2018) "Financing the Response to Climate Change: The Pricing and Ownership of U.S. Green Bonds," Technical Report w25194, National Bureau of Economic Research, [ $10.3386 / \mathrm{w} 25194$.

Bertrand, Marianne, Esther Duflo, and Sendhil Mullainathan (2004) "How much should we trust differences-in-differences estimates?" The Quarterly journal of economics, 119 (1), 249-275.

Breedon, Francis, Jagjit S Chadha, and Alex Waters (2012) "The financial market impact of UK quantitative easing," Oxford Review of Economic Policy, 28 (4), 702-728.

Campiglio, Emanuele, Yannis Dafermos, Pierre Monnin, Josh Ryan-Collins, Guido Schotten, and Misa Tanaka (2018) "Climate change challenges for central banks and financial regulators," Nature Climate Change, 8 (6), 462-468, 10.1038/s41558-018-0175-0.

Chava, Sudheer (2014) "Environmental externalities and cost of capital," Management Science, 60 (9), 2223-2247.

Christensen, Jens HE and Glenn D Rudebusch (2012) "The response of interest rates to US and UK quantitative easing," The Economic Journal, 122 (564), F385-F414.

Dafermos, Yannis, Daniela Gabor, Maria Nikolaidi, Adam Pawloff, and Frank van Lerven (2020) "Decarbonising is easy: Beyond market neutrality in the ECB's corporate QE," October, https://neweconomics.org/2020/10/decarbonising-is-easy, Library Catalog: eprints.soas.ac.uk, Publisher: New Economics Foundation.

De Santis, R.A., Andre Geis, Aiste Juskaite, and Lia Vaz Cruz (2018) "The impact of the corporate sector purchase programme on corporate bond markets and the financ- 
ing of euro area non-financial corporations," Economic Bulletin Articles, 3, https:// econpapers.repec.org/article/ecbecbart/2018_3a0003_3a2.htm, Publisher: European Central Bank.

De Santis, R.A. and Andrea Zaghini (2019) "Unconventional Monetary Policy and Corporate Bond Issuance," (ID 3486802), https://papers.ssrn.com/abstract=3486802

Duca, Marco Lo, Giulio Nicoletti, and Ariadna Vidal Martinez (2016) "Global corporate bond issuance: what role for US quantitative easing?" Journal of International Money and Finance, 60, 114-150.

Flammer, Caroline (2020) "Corporate Green Bonds," SSRN Scholarly Paper ID 3125518, Social Science Research Network, Rochester, NY, 10.2139/ssrn.3125518.

Fratzscher, Marcel, Marco Lo Duca, and Roland Straub (2018) "On the international spillovers of US quantitative easing," The Economic Journal, 128 (608), 330-377.

Goss, Allen and Gordon S. Roberts (2011) "The impact of corporate social responsibility on the cost of bank loans," Journal of Banking \& Finance, 35 (7), 1794-1810, 10.1016/ j.jbankfin.2010.12.002.

Joyce, Michael AS, Ana Lasaosa, Ibrahim Stevens, and Matthew Tong (2011) "The financial market impact of quantitative easing in the United Kingdom," 26th issue (September 2011) of the International Journal of Central Banking.

Kapraun, Julia and Christopher Scheins (2019) “(In)-Credibly Green: Which Bonds Trade at a Green Bond Premium?" SSRN Scholarly Paper ID 3347337, Social Science Research Network, Rochester, NY, 10.2139/ssrn.3347337.

Karpf, Andreas and Antoine Mandel (2018) "The changing value of the âgreenâ label on the US municipal bond market," Nature Climate Change, 8 (2), 161-165, 10.1038/ s41558-017-0062-0.

Krishnamurthy, Arvind and Annette Vissing-Jorgensen (2011) "The effects of quantitative easing on interest rates: channels and implications for policy," National Bureau of Economic Research.

Matikainen, Sini, Emanuele Campiglio, and Dimitri Zenghelis (2017) The climate impact of quantitative easing, $10.13140 /$ RG.2.2.24108.05763. 
Meaning, Jack and Feng Zhu (2011) "The impact of recent central bank asset purchase programmes," BIS Quarterly Review, December.

Rogers, John H, Chiara Scotti, and Jonathan H Wright (2014) "Evaluating asset-market effects of unconventional monetary policy: a multi-country review," Economic Policy, 29 (80), 749-799.

Svartzman, Romain, Patrick Bolton, Morgan Despres, Luiz Awazu Pereira Da Silva, and Frederic Samama (2020) "Central banks, financial stability and policy coordination in the age of climate uncertainty: a three-layered analytical and operational framework," Climate Policy, 0 (0), 1-18, 10.1080/14693062.2020.1862743.

Swanson, Eric T (2020) "Measuring the effects of Federal Reserve forward guidance and asset purchases on financial markets," Journal of Monetary Economics.

Tang, Dragon Yongjun and Yupu Zhang (2020) "Do shareholders benefit from green bonds?" Journal of Corporate Finance, 61, 101427, 10.1016/j.jcorpfin.2018.12.001.

Todorov, Karamfil (2020) "Quantify the quantitative easing: Impact on bonds and corporate debt issuance," Journal of Financial Economics, 135 (2), 340-358, 10.1016/j. jineco.2019.08.003.

Yang, Zihui and Yinggang Zhou (2017) "Quantitative easing and volatility spillovers across countries and asset classes," Management Science, 63 (2), 333-354.

Zaghini, Andrea (2019) "The CSPP at work: Yield heterogeneity and the portfolio rebalancing channel," Journal of Corporate Finance, 56, 282-297.

Zerbib, Olivier David (2019) "The effect of pro-environmental preferences on bond prices: Evidence from green bonds," Journal of Banking \& Finance, 98, 39-60, 10.1016/j. jbankfin.2018.10.012.

\section{A. Appendix}

\section{A.1. Appendix A: Data details}




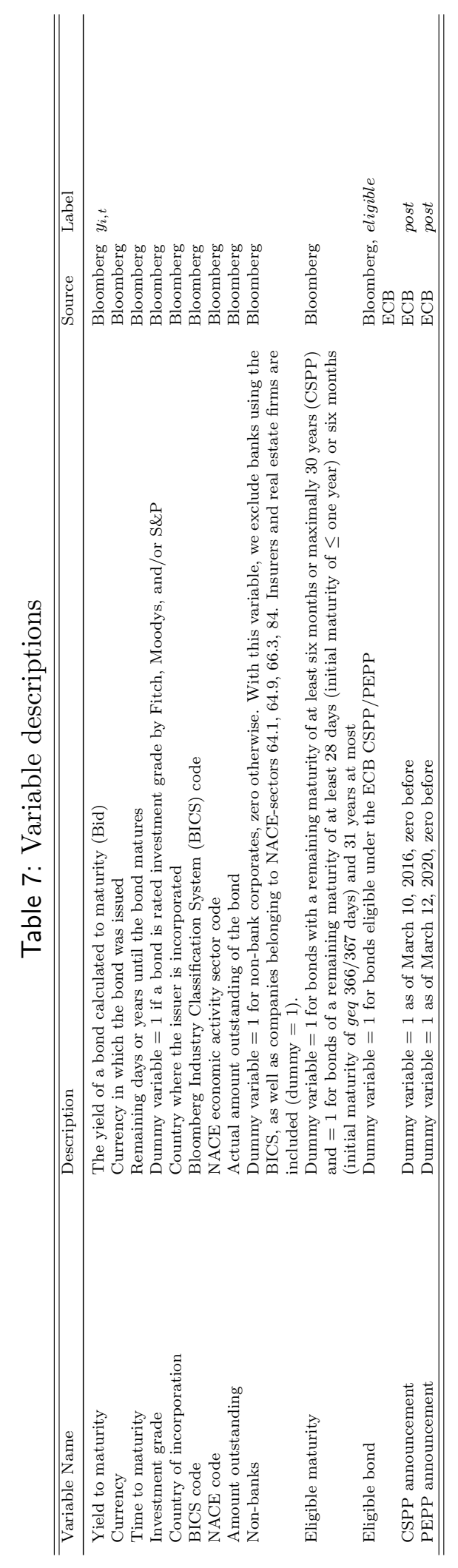

